\title{
LA ECONOMÍA DE LEÓN EN EUROPA: 1986-2011 EL SISTEMA SANITARIO
}

\author{
Cristina Gutiérrez López \\ Contabilidad Analítica \\ Departamento de Dirección y Economía de la Empresa \\ Universidad de León \\ cristina.gutierrez.lopez@unileon.es
}

\begin{abstract}
1. Introducción - 2. El sistema nacional de salud: 2.1. Marco legislativo - 3. El modelo de financiación sanitario: 3.1. Financiación autonómica: condicionantes, 3.2. El caso concreto del sistema sanitario 4. Gasto sanitario: 4.1. Copago, 4.2. Gasto farmacéutico - 5. Gestión sanitaria - 6. Actualidad y últimas reformas - 7. El sistema sanitario en la provincia de León (1986-2011): 7.1. Recursos, dotación sanitaria y actividad, 7.2. Recursos humanos, 7.3. Gasto sanitario en Castilla y León, 7.4. Situación actual: León en perspectiva -8 . Conclusiones - Referencias
\end{abstract}

\section{Introducción}

Las últimas reformas relativas al sistema sanitario español han cuestionado por primera vez un modelo que desde mediados de los ochenta -con la aprobación de la Ley General de Sanidad-avanzaba hacia la universalización de la atención sanitaria, la integración de los dispositivos sanitarios de titularidad pública en un Servicio Nacional de Salud (SNS), la progresiva financiación mediante presupuestos generales y el traspaso de competencias a las Comunidades Autónomas (en adelante, CC.AA.). Además, la difícil financiación y organización de una atención sanitaria pública para la práctica totalidad de la población se ha agravado a consecuencia del gradual envejecimiento de la población, el incremento de la demanda asistencial y las ineficiencias en el diseño del sistema.

La Ley General de Sanidad de 1986 incluye el reconocimiento del derecho a la protección de la salud (recogido en la Constitución Española) y la organización sanitaria acorde a la definición del papel de las CC.AA., sobre las que se articula el SNS. Asimismo, la propia Constitución, en el artículo 148.1.21, recoge que las Comunidades Autónomas "podrán asumir competencias en materia de sanidad e higiene", facultad que han ejercitado.

La gestión de la red hospitalaria se ha caracterizado, en distintas etapas, por un cambio desde la definición de presupuestos individualizados por centro y no vinculados a su actividad (desde la Ley General de Sanidad hasta comienzos de los noventa) hacia contratos entre el INSALUD (Instituto Nacional de Salud) y los centros hospitalarios, combinando la hegemonía regulatoria con una creciente autonomía de los centros (1992-1997), llegando finalmente a la descentralización en la gestión (desde 1997).

De igual modo, desde comienzos de los años noventa, la organización de la asistencia especializada pública (tradicionalmente estruc- 
turada en los niveles hospital y ambulatorio) ha tendido a la unificación e integración funcional del hospital y los centros de especialidades en un único nivel de asistencia especializada, con características particulares en las distintas CC.AA. debido especialmente al proceso de transferencia de las funciones y los servicios sanitarios a éstas culminado en 2002, y a la creación simultánea (RD 840/2002) de un nuevo organismo denominado Instituto de Gestión Sanitaria, al que corresponde la gestión de los derechos y obligaciones del INSALUD y las prestaciones sanitarias en el ámbito de las ciudades de Ceuta y Melilla.

EI SNS ha transferido sus competencias a raíz del modelo de financiación autonómica acordado en 2001, siendo ahora las CC.AA. las responsables de gestionar los servicios sanitarios integrados en sus servicios de salud y obteniendo capacidad plena para determinar sus políticas de gasto, mientras que ciertas competencias, como la coordinación general, corresponden aún a la Administración General del Estado.

Este modelo sanitario, financiado con impuestos y que ha presumido de su cobertura universal, constituye uno de los principales sectores económicos del país -ocupa a más de un millón de personas en el ámbito público- y ha logrado buenos resultados con un gasto agregado relativamente modesto, pero aún persisten importantes desigualdades en salud entre grupos sociales y regiones, sin que en los últimos años se haya producido un proceso de convergencia en salud en el conjunto español (Martín y López, 2011).

Durante los años de expansión económica, el gasto sanitario público de las CC.AA. aumentó a una tasa superior al crecimiento del PIB, y en el período 1999-2005 el gasto medio por persona protegida tuvo un crecimiento medio anual del $7,16 \%$. Sin embargo, no cualquier incremento del gasto sanitario se traduce en mejoras de salud de la población, siendo inevitable reconocer el papel del buen gobierno sanitario para evitar que el incremento del gasto sanitario se disipe sin repercusiones positivas en la salud y la calidad de vida.
El último cambio en el sistema sanitario español, no sólo normativo sino de filosofía, derivado del Real Decreto-Ley 16/2012, de 20 de abril, de medidas urgentes para garantizar la sostenibilidad del Sistema Nacional de Salud, caracteriza un sistema que deja de ser universal pues, como indica, "la asistencia sanitaria en España, con cargo a fondos públicos, a través del Sistema Nacional de Salud, se garantizará a aquellas personas que ostenten la condición de asegurado", de modo que el derecho a la asistencia sanitaria está vinculado ahora a la condición de asegurado o beneficiario de la Seguridad Social y no de ciudadano o empadronado español.

Esta exclusión de los inmigrantes empadronados y sin permiso de residencia en la protección del sistema nacional de salud ${ }^{1}$ puede motivar un aumento del uso de los servicios de urgencias así como mayores costes de medio y largo plazo como consecuencia de la no atención (López-Fernández et al, 2012). A este significativo y profundo cambio -así como la situación de los jóvenes mayores de 26 años que no hayan entrado en el sistema de seguridad social o las mujeres que no trabajen fuera de casa, condicionadas a sus parejas- se suman las nuevas fórmulas de copago (con especial efecto sobre enfermos crónicos) y la ordenación de la cartera de servicios, entre otros. Todo ello puede traducirse en un mayor gasto en salud para los ciudadanos, bajo la premisa de que los sistemas basados en el aseguramiento son más caros que los servicios nacionales de salud basados en impuestos.

Sobre esta base, en este trabajo se revisan los rasgos del SNS y las principales normativas que caracterizan y condicionan su funcionamiento, repasando a continuación las características del sistema de financiación autonómica y su aplicación al sistema sanitario, así como las alternativas para racionalizar el gasto sanitario, centradas en el copago y el comportamiento del gasto farmacéutico. Asimismo, se plantean las particularidades de la gestión sanitaria y las grandes líneas de la última reforma, justificada por la necesidad de

1 El colectivo inmigrante puede usar los servicios de urgencia, atención al embarazo, parto y posparto, pero no dispondrá de tarjeta sanitaria. 
racionalizar el gasto sanitario. A continuación, se resumen los principales datos e indicadores sanitarios de la provincia de León y la Comunidad Autónoma de Castilla y León desde 1986, considerando también cifras sobre financiación y gasto sanitario, así como la situación actual de la provincia a la luz de los últimos informes publicados, relativos a 2011. El capítulo concluye planteando las conclusiones más significativas.

\section{2. 日 Sistema Nacional de Salud}

EI SNS español actual surge históricamente a mediados del siglo pasado inspirado en los modelos continentales europeos de Seguridad Social, aunque a diferencia de ellos crea una extensa red propia de centros y organizaciones de carácter ambulatorio y hospitalario. INSALUD, creado en 1978 como un órgano gestor de las prestaciones sanitarias de la Seguridad Social, acogió esta estructura de oferta, configurándose como una gran organización fuertemente centralizada que daba cobertura sanitaria directa a más del $84 \%$ de la población.

Realizada la transición democrática y con la Constitución, la Ley General de Sanidad de 1986 inició el proceso de transformación del sistema de Seguridad Social en un modelo tipo SNS, definido en el artículo 44.2 como "el conjunto de los servicios de salud de la administración del estado y de los servicios de salud de las CC.AA. en los términos establecidos por la presente Ley" e identificando como principios fundamentales la universalidad en el acceso, la descentralización en la gestión, la equidad en el acceso a los servicios y prestaciones, la financiación pública y la participación social.

El sistema fue evolucionando hacia un modelo financiado por impuestos generales, de cobertura casi universal, que coexiste con un importante sector de seguros privados que dan cobertura aproximadamente al $20 \%$ de la población.

\subsection{Marco legislativo}

La Ley 14/1986, de 25 de abril, o Ley General de Sanidad, es el elemento básico de constitución del SNS, pues se concibió para diseñar la configuración de los servicios sanitarios del Estado: cobertura sanitaria en términos de población y prestaciones cubiertas, financiación y organización de la provisión de servicios sanitarios, gestión de éstos por parte de sus distintos componentes, relación con los proveedores y entre niveles de atención, condiciones laborales y organizativas del personal sanitario, etc. La práctica, sin embargo, dado que su aplicación integral hubiera supuesto transformar el sistema sanitario preexistente que, en ese momento, cubría al $90 \%$ de la población, hizo que la norma se llenara de plazos transitorios (Rey del Castillo, 2011).

Esta Ley supuso la transición formal de un sistema de seguridad social (modelo Bismarck) a un servicio nacional de salud (modelo Beveridge), avanzando progresivamente desde el modelo de financiación mediante cotizaciones a la Seguridad Social a otro financiado básicamente por impuestos generales, con la excepción de las tres mutualidades con financiación pública (MUFACE -mutualidad general de funcionarios civiles del Estado-, MUGEJU -mutualidad general judicial- e ISFAS -instituto social de las fuerzas armadas-), a las que sólo pueden acceder los funcionarios públicos y que tienen estatutos cuasi-públicos. En la práctica esto supone que los funcionarios son el único grupo que puede elegir libremente entre la cobertura el SNS y la provisión privada.

A partir de este marco general, la Ley 15/1990, de 9 de julio, de ordenación sanitaria de Cataluña, marcó un punto y aparte al dar inicio a una nueva forma de gestión del SNS español que pronto fue adoptado por otras CC.AA., tal que éstas elaboraron normas sobre servicios de salud. Esta ley dotó al Servicio catalán de salud, creado por la norma, de una naturaleza distinta a la del INSALUD, como organismo autónomo de carácter administrativo, y cuya gestión en 1990 había sido traspasada ya a seis CC.AA.

Por su parte, la Ley 15/1997 sobre nuevas formas de gestión del SNS, promulgada por el Partido Popular en un marco de consenso, reconoció legalmente esas nuevas formas de gestión generadas por las distintas CC.AA. y 
que ya se venían sucediendo. En su concreción real, se tradujo en la creación -bajo la modalidad PFI o Iniciativa de Financiación Privada- del Hospital de Alzira, con el patrocinio de un consorcio en el que participaba la aseguradora privada Adeslas. Así se inició un proceso de entrada de las aseguradoras privadas en la gestión del SNS, primero en Valencia y luego en Madrid.

En términos de financiación sanitaria, se trataba de un sistema diferenciado imperfecto, donde los ingresos contributivos basados en aportaciones de trabajadores y empresarios fueron siendo sustituidos por aportaciones fiscales, en un proceso cerrado en 1999. El sistema siguió desde entonces siendo teóricamente finalista, si bien de forma más formal que real, pues desde que se inició el traspaso del INSALUD a las CC.AA., éstas integraron la financiación recibida para su dedicación a la asistencia sanitaria en la masa presupuestaria común, que luego distribuían según sus propios criterios. El nuevo sistema de financiación coincidió con el cierre del proceso de descentralización de la asistencia sanitaria en las diez CC.AA. que no habían recibido aún el traspaso.

La Ley Orgánica 7/2001, de 27 de diciembre, de modificación de la Ley Orgánica $8 / 180$, de financiación de las CCAA (LOFCA), y la Ley 21/2011, de 27 de diciembre, por la que se regulan medidas fiscales y administrativas del nuevo sistema de financiación de las CC.AA. de régimen común, configuran las nuevas normativas de financiación autonómica, diseñadas para dotar a cada Comunidad de fondos suficientes para afrontar los servicios que debe atender, siendo para ello necesario traspasar los servicios sanitarios, cediéndolas así el amplio paquete de impuestos que caracterizaron el nuevo sistema, cesión que no hubiera podido justificarse sin el traspaso de los servicios.

Además de las normativas anteriores, otras leyes merecen ser citadas, particularmente algunas promulgadas en 2003 , si bien no han afectado de forma sustancial al funcionamiento del SNS. Es el caso de la Ley 16/2003, de 26 de mayo, de Cohesión y calidad del SNS, la ley
44/2003, de 21 de noviembre, de ordenación de las profesiones sanitarias, y la ley $55 / 2003$, de 16 de noviembre, por la que se aprobó el estatuto marco del personal estatutario de los servicios de salud.

En el ámbito farmacéutico, la ley del Medicamento (ley 25/1990, modificada en 2006), propició la convergencia de la normativa española con la europea en materia de medicamentos, incluyendo el sistema de patentes. Sin embargo, no ha logrado cambiar la relación a través de convenios entre proveedores de uno y otro nivel -industria y oficinas de farmacia- y el SNS, sin acentuar el poder de compra del que una actuación coordinada del SNS podría beneficiarse. Esto se traduce, como se verá en el cuarto epígrafe, en un elevado gasto en productos farmacéuticos sobre el gasto sanitario total, situado por encima del promedio de otros países europeos.

El Real Decreto-Ley 16/2012, de 20 de abril, de medidas urgentes para garantizar la sostenibilidad del Sistema Nacional de Salud y mejorar la calidad y seguridad de sus prestaciones, representa la Reforma Sanitaria que el sistema afronta actualmente, reflejada en un notable cambio de filosofía y el fin de la cobertura universal.

Esta reforma se justifica por las graves dificultades económicas por las que atraviesa el SNS y la búsqueda de una mayor eficacia en la gestión de los recursos disponibles, así como la mejora de la coordinación entre los servicios de salud autonómicos y el uso racional y la adecuación terapéutica a la duración real de los tratamientos. Según apunta el texto de la norma, el objetivo de las nuevas medidas define una "reforma estructural del SNS dotándolo de solvencia, viabilidad y reforzando las medidas de cohesión para hacerlo sostenible en el tiempo", y se concreta principalmente en las áreas siguientes:

- Definición de asegurado: trabajadores por cuenta ajena o propia afiliados a la Seguridad Social y en situación de alta, pensionistas de la Seguridad Social, perceptores de otra prestación periódica de la Seguridad Social (incluida la prestación por desempleo), y personas que figuran inscritas como deman- 
dantes de empleo y que han agotado las prestación por desempleo. Además, las personas de nacionalidad española o de estados miembros de la Unión Europea, Espacio Económico Europeo o Suiza residentes en España, y los extranjeros con autorización, estarán asegurados siempre que no superen ciertos umbrales de renta. Por su parte, serán beneficiarios de un asegurado los cónyuges $o$ personas con relación análoga de afectividad, así como los descendientes a su cargo menores de 26 años o con discapacidad al menos de un $65 \%$. Esto deja fuera a los mayores de 26 años sin trabajo o en alguna de las definiciones iniciales y a los extranjeros que no han regularizado su situación, si bien sobre estos últimos, para los mayores de 18 años -los menores recibirán asistencia igual que los españoles- la normativa indica que recibirán asistencia sanitaria de urgencia por enfermedad grave o accidente y asistencia al embarazo, parto y posparto.

- Categorización de la cartera de servicios, definiendo la cartera común básica, suplementaria y de servicios accesorios del SNS.

- Prestación farmacéutica: se indica cómo se procederá en las prescripciones de medicamentos, señalando que cuando se realice por principio activo (procesos agudos y procesos crónicos) el farmacéutico dispensará el medicamento de menor precio. Además se señala cómo se calculará el precio de referencia al que se somete la financiación pública de medicamentos, definido en base al menor coste/tratamiento/día de los conjuntos de medicamentos presentados. Además, se modifica la aportación de los beneficiarios en la prestación farmacéutica ambulatoria, en función del nivel de renta y sujetos a topes máximos. De este modo, sólo estarán exentos de cualquier pago las personas que reciben rentas de integración social, pensiones no contributivas, los parados que ya no perciben el subsidio de desempleo y los tratamientos por accidente de trabajo y enfermedad profesional.

- Recursos humanos: definición homogénea de la regulación de categorías profesionales y criterios que regulan el sistema retributivo.

\section{E modelo de financiación sanitario}

Los principales cambios del modelo de financiación sanitaria se centran en la configuración autonómica del Estado y las transferencias sanitarias, y el desplazamiento de la fuente de financiación de la Seguridad Social a los impuestos (Sánchez Bayle, 2011).

\subsection{Financ iación autonómica: condicionantes}

El proceso de descentralización español se inicia en la Constitución Española, siendo los artículos 2 y 137 los pilares para la creación y desarrollo del Estado de las Autonomías. Esta normativa señala como orientadores del sistema de financiación autonómica a los principios de (Herrero Alcalde y Tránchez Martín, 2011; De la Fuente, 2012):

- Autonomía: la descentralización del sector público puede implicar una gestión más eficiente de los servicios en la medida en que los gobiernos subcentrales, por su mayor proximidad con el ciudadano, tienen más y mejor información acerca de las necesidades y preferencias de éste, lo que les permite adecuar en mayor medida la prestación de los servicios públicos a las particulares necesidades de su territorio.

- Suficiencia: todas las CC.AA. deben disponer de los ingresos necesarios (suficientes) para financiar los servicios transferidos por la Administración General del Estado.

- Solidaridad: es necesario que el gobierno central efectúe redistribuciones interterritoriales de recursos, con el objeto de reducir las diferencias existentes en los niveles de renta y de servicios públicos y coordinación.

En el caso de la descentralización española, se produce una financiación autonómica asimétrica, debido a la existencia del régimen foral de Navarra y el País Vasco, aunque hay otras cuestiones que afectan de forma particular a algunas Comunidades. Así, la Constitución española establece dos vías para acceder al autogobierno: la más restrictiva (artículo 151) permite a las comunidades pasar a gestionar de manera inmediata las políticas sanitaria y educativa, y la menos exigente (artículo 143) prevé esperar al menos seis años para poder 
recibir los traspasos en educación y sanidad. Como consecuencia de esto, los territorios que accedieron a la autonomía por la vía del artículo 143 no culminaron el proceso de descentralización del gasto hasta 2002, año en que finalizó el traspaso de los servicios sanitarios.

\section{2. 日 caso conc reto del sistema sanitario}

El proceso de transferencia de competencias a servicios regionales de salud conjuga su principal virtud con su mayor defecto: el objetivo de las autoridades sanitarias regionales exclusivamente en su territorio difumina un punto de vista general sobre el sistema nacional de salud. Hasta 2001, el Ministerio de Economía y Hacienda establecía el presupuesto para sanidad según lo indicado por la LOFC (ley orgánica de financiación de las CC.AA.), siendo éste de carácter finalista, mientras que el Ministerio de Sanidad administraba la parte correspondiente al territorio del INSALUD y participaba en las negociaciones bilaterales.

Para las CC.AA. no había ningún techo de gasto explícito, por lo que estaban autorizadas a generar un déficit y trasladarlo al siguiente período presupuestario. Ese déficit -transformado en deuda histórica al acumularse durante añosera asumido por la Administración central como base para el cálculo del siguiente incremento, de modo que el gobierno central reembolsaba la deuda.

En 2001 se produjo el primer intento de introducir el principio de corresponsabilidad fiscal en la financiación de los sistemas regionales de salud, tal que se aprobó un nuevo sistema de financiación centrado en los problemas de la financiación anterior: suficiencia (todas las CC.AA. debían contar con ingresos suficientes para financiar los servicios) y solidaridad entre territorios a través de políticas de redistribución. El cambio suponía que la financiación no era finalista, sino que estaba incluida en los fondos totales asignados a cada Comunidad, de modo que los propios gobiernos regionales determinaban el presupuesto para sanidad. Además, la fórmula de asignación pasaba a basarse en un criterio per cápita ponderado por la dispersión de la población, la extensión y la insularidad del territorio. Además, se reconocía cierta autonomía a los gobiernos regionales para regular determinados componentes del sistema tributario nacional. Así, el montante de la financiación se obtenía con la cesión directa a las regiones de parte de los ingresos tributarios generados en el territorio de cada Comunidad pero recaudados por la Administración central: $40 \%$ del IRPF, $35 \%$ del IVA, $40 \%$ de otros impuestos indirectos, $100 \%$ del impuesto sobre la electricidad, impuesto de sociedades, sucesiones y donaciones, e impuesto sobre patrimonio.

Dado que el sistema establece la existencia de mecanismos de nivelación regional y solidaridad interterritorial, los fondos asignados con cargo al Fondo de suficiencia se calculan en función de la diferencia entre los ingresos generados en una Comunidad y la necesidad real de gasto según la población ajustada. Así, mientras que las CC.AA. más prósperas tienen un saldo negativo y son contribuyentes netas al Estado, otras son perceptoras netas.

Hasta el sistema aprobado en 2001, persistió un importante flujo de transferencias condicionadas, las procedentes del INSALUD, que debían destinarse a financiar el Sistema Regional de Salud.

Por todo lo anterior, en el caso del sistema sanitario, la financiación autonómica presenta problemas debido a su carácter complejo y opaco, su dependencia de la recaudación de tributos regionales, y la inexistencia de criterios sólidos de definición de necesidad relativa en sanidad. Además, el carácter no finalista de los recursos sanitarios dificulta al Estado poder garantizar unos niveles de gasto sanitario público per cápita adecuadamente distribuidos.

Los mecanismos de financiación han sufrido bastantes transformaciones:

- Antes de la Ley General de Sanidad, más de un centenar de organismos públicos tenían dispositivos asistenciales con escasa coordinación, y con financiación independiente. Cada organismo destinaba una parte de sus presupuestos a la sanidad, con criterios distintos y pocas veces complementarios.

- Entre la Ley General de Sanidad y el Pacto de Toledo (1995) la financiación cambió por dos 
procesos de transferencias hacia las CC.AA., recibidas desde los ayuntamientos, diputaciones, etc., y desde las redes públicas de titularidad estatal -todas las CC.AA. de la Administración Institucional de la Sanidad Nacional (AISNA) y algunas CC.AA. del INSALUD-. Este proceso fue anterior en el caso de Cataluña (1981) y posterior en otros, de forma paulatina (hasta Canarias, en 1993). La financiación de cada transferencia se realizó mediante una negociación entre cada Comunidad y el Ministerio de Sanidad (que gestionaba el INSALUD) y se realizó en términos económicos muy diferentes según cada una de ellas, según presiones y/o afinidades políticas.

- Del Pacto de Toledo al fin de las transferencias (2001). En el Pacto de Toledo se acordó desvincular la financiación sanitaria de la Seguridad Social por dos motivos: asegurar la autofinanciación del sistema de seguridad social y circunscribirlo al marco normativo, y evitar el paso intermedio de transferencias del Estado a la Seguridad Social y de ésta al sostenimiento del SNS. Por tanto, el modelo de financiación pasó a ser una transferencia para la atención sanitaria en los presupuestos generales del Estado a las CC.AA.

- Fin de las transferencias a las CC.AA. y nuevo modelo de financiación. En diciembre de 2001 finalizan las transferencias del INSALUD a todas las CC.AA. y se pone en marcha un nuevo modelo de financiación caracterizado por una desigual asignación de fondos: el fondo inicial se negoció individualmente con las CC.AA. sobre la base del presupuesto liquidado del INSALUD y por el censo de población de 1999, resultando una notable diferencia entre Comunidades, transferencias no finalistas e impuestos cedidos, que dado la reducción de los impuestos sobre los que las CC.AA. tienen capacidad normativa, llevan a medidas como el céntimo sanitario.

La descentralización sanitaria presenta no obstante algunas ventajas que caracterizan a nuestro SNS como uno de los mejores del mundo como modelo de sanidad universal, con un catálogo de los más completos de Europa, profesionales bien formados, buena atención primaria, amplias infraestructuras y buena dotación tecnológica (Lamata Cotanda, 2011), si bien algunos trabajos apuntan sobre la necesidad de reformar la atención primaria (Campos y Aguiar, 2013).

Sin embargo, esta gestión sanitaria autonómica sin ningún instrumento de coordinación efectivo ha llevado a que las partidas sanitarias sean en buena parte de las CC.AA. la causa más importante de sus déficits (algo que no sorprende dado que el sistema sanitario representa alrededor del $40 \%$ del gasto y presupuesto de las CC.AA.), que son la parte más importante del déficit público. El sistema sanitario público tiende a gastar por encima de los presupuestos autorizados por los parlamentos autonómicos, dando lugar periódicamente a operaciones extraordinarias de saneamiento del déficit acumulado por las CC.AA. por parte del gobierno central. La tendencia a que el gasto sanitario crezca por encima del crecimiento del PIB puede crear un déficit no reconocido.

No obstante, el problema de la insostenibilidad de la sanidad no es un exceso de gasto para el nivel de prestaciones garantizadas, sino de insuficiencia de ingresos fiscales. El problema del déficit sanitario se transforma entonces en una insuficiencia de financiación autonómica, agravada por el hecho de que la sanidad no se financia con un presupuesto específico, tratándose de financiación no finalista para cada competencia, una financiación global que gestiona un parlamento.

La medición de las necesidades de gasto sanitarias, que partió de emplear la población (protegida) total como referencia, ha pasado a tener en cuenta que no todos los grupos demográficos emplean los servicios públicos con la misma intensidad. Como se ha mencionado, en 2001 se acordó distribuir los recursos destinados a mantener el SNS teniendo en cuenta que la población mayor de 65 años genera un gasto sanitario relativamente mayor que la población joven. Y en 2009 se decidió emplear un indicador de necesidades basado en "unidades de gasto equivalentes", construido a partir de grupos de población segmentados por estratos de edad, ponderados por el consumo relativo que cada uno de ellos hace de los servicios sanitarios.

Respecto a las perspectivas sobre la evolución del gasto sanitario, el crecimiento de éste derivado del impacto demográfico -por el 
aumento de la población y el envejecimientoserá probablemente inferior al PIB, mientras que el aumento del porcentaje de PIB destinado a financiación sanitaria depende del ritmo de aumento de factores endógenos, como los precios de los inputs, el cambio tecnológico, las nuevas prestaciones, etc. (Martín y López, 2011).

Entre las soluciones contra los desequilibrios recaudatorios y presupuestos se plantean sistemas de información homologables, actualizados y desagregados, la financiación sanitaria con carácter finalista y el desarrollo del plan integrado de salud. El acuerdo de 18 de marzo de 2010 entre las CC.AA. y el Ministerio de sanidad y política social incluye medidas como las siguientes: extender la historia clínica digital común, establecer medidas de contención del gasto farmacéutico, avanzar en criterios comunes para las retribuciones del personal sanitario, ofrecer mecanismos para compras concertadas, fortalecer los sistemas de información común, elaborar una estrategia común para pacientes crónicos, reforzar el papel de evaluación de tecnologías sanitarias para garantizar criterios de seguridad y coste-efectividad en la autorización de nuevas prestaciones y su uso, etc.

En definitiva, la causa que parece justificar realmente las desviaciones en el gasto sanitario radica en las propias características del sistema de financiación, que pretende reproducir un modelo federal pero dista mucho del disponible por países cuya organización realmente reproduce ese esquema.

\section{Gasto sanitario}

La composición del gasto sanitario en España puede observarse en la Tabla 1, tanto desde una perspectiva económico-presupuestaria -atendiendo a la naturaleza del gasto- como desde un punto de vista funcional. En el primer caso, son los gastos de personal los que representan más del $45 \%$ del gasto, y en el segundo destacan los gastos en servicios hospitalarios (54\%) seguidos del gasto en farmacia (22\%).

Tabla 1

Composición del gasto consolidado sanitario total CC.AA. (1999-2005)

\begin{tabular}{|c|c|c|c|}
\hline & 1999 & 2003 & 2005 \\
\hline \multicolumn{4}{|l|}{ CLASIFICACIÓN ECONÓMICO-PRESUPUESTARIA } \\
\hline Remuneración del personal & 13.408 .060 & 17.744 .707 & 20.896.147 \\
\hline Consumo intermedio & 5.097 .867 & 7.980 .965 & 9.808 .360 \\
\hline Conciertos & 1.481 .428 & 2.008 .048 & 2.370 .213 \\
\hline Transferencias corrientes & 6.438 .942 & 9.463 .513 & 10.865 .438 \\
\hline Gasto de capital & 945.926 & 1.502 .377 & 1.824 .339 \\
\hline \multicolumn{4}{|l|}{ CLASIFICACIÓN FUNCIONAL } \\
\hline Servicios hospitalarios y especializados & 14.967 .851 & 20.674 .016 & 24.889 .036 \\
\hline Servicios primarios de salud & 3.975 .414 & 5.557 .683 & 6.445 .978 \\
\hline Servicios de salud pública & 263.494 & 371.369 & 495.398 \\
\hline Servicios colectivos de salud & 497.247 & 804.840 & 913.258 \\
\hline Farmacia & 6.230 .317 & 9.033 .552 & 10.261 .956 \\
\hline Traslado, prótesis y aparatos terapéuticos & 388.518 & 567.958 & 701.971 \\
\hline Gasto de capital & 924.136 & 1.460 .083 & 1.787.084 \\
\hline Transferencias a otros sectores & 125.245 & 230.109 & 269.816 \\
\hline TOTAL GASTO CONSOLIDADO DEL SECTOR CCAA & 27.372.222 & 38.699 .611 & 45.764.498 \\
\hline
\end{tabular}

Fuente: Informe del grupo de trabajo de análisis del gasto sanitario (2007).

Datos en miles de euros. 
En atención a la importancia del gasto farmacéutico, según el artículo 149.1 de la Constitución, es competencia exclusiva del Estado establecer las bases y coordinación general de la sanidad y regular la legislación sobre productos farmacéuticos. Sobre esta base, las actuaciones de la Administración en esta línea se han orientado hacia un doble objetivo: garantizar un uso racional de los medicamentos y una prestación farmacéutica adecuada (Gallego Peragón, 2011).

En la Unión Europea, la potestad para fijar el precio de los medicamentos está sujeta a los requisitos de transparencia y no discriminación establecidos por la normativa comunitaria (Directiva 89/105/CEE del Consejo, de 21 de diciembre, de transparencia de las medidas que regulan la fijación de precios de los medicamentos para uso humano y su inclusión en el ámbito de los sistemas nacionales del seguro de enfermedad). La normativa comunitaria parte de la idea que la ordenación de precios de los medicamentos y la organización de los sistemas de Seguridad Social es una competencia reservada a los Estados miembros, si bien éstos han de respetar dos principios: no discriminación (no favorecer los productos farmacéuticos nacionales en detrimento de los procedentes de otros Estados miembros) y transparencia (las decisiones sobre fijación de precios deben ser motivadas y adoptadas en función de criterios objetivos y verificables).

En atención a estos principios, las últimas medidas adoptadas sobre eficiencia del gasto sanitario se centran en modificaciones del sistema de precios de referencia y reducción del precio de medicamentos genéricos.

El gasto farmacéutico, representa, en el caso español, uno de los más elevados de Europa y la OCDE respecto al gasto sanitario total, debido al uso reducido de genéricos, la prescripción de fármacos inadecuados, estrategias de marketing de la industria farmacéutica, uso de "fármacos de marca", etc.

Los medicamentos genéricos son productos de eficacia clínica demostrada (idéntica calidad, seguridad y eficacia) pero más económicos pues ha expirado el período de exclusividad de datos del medicamento original o marca. Aparecieron en España en 1997, completando un mercado farmacéutico compuesto hasta entonces sólo por especialidades farmacéuticas originales (comercialización por el mismo laboratorio que ha realizado su I+D), licenciales y "copias o registro-copias" (medicamentos con el mismo principio activo y forma farmacéutica que la especialidad original, pero con procesos de fabricación diferentes).

Dos recientes decretos intentan reducir el coste financiero de la prestación farmacéutica:

- Real Decreto-ley 4/2010, de 26 de marzo, de racionalización del gasto farmacéutico con cargo al SNS, con el objetivo de modificar la financiación pública de medicamentos y productos sanitarios para simplificar la aplicación del sistema de precios de referencia -por encima de los cuales se excluye la cobertura pública- mientras se acuerda la reducción del precio de medicamentos genéricos.

- Real Decreto-ley 8/2010, de 20 de mayo, por el que se adoptan medidas extraordinarias para la reducción del déficit público, que incluyen la revisión del precio de medicamentos excluidos del sistema de precios de referencia y la adecuación del número de unidades de los envases de los medicamentos a la duración estandarizada de los tratamientos, así como la dispensación de medicamentos en formato unidosis. En particular, recoge una serie de reducciones sobre los márgenes de beneficio de los medicamentos que se dispensen en oficinas de farmacia con cargo a la prestación farmacéutica del SNS -que el artículo 8 fija en el 7,5\% el precio de venta al público-.

\subsection{Copago}

En términos generales, la parte de la renta de un país destinada a salud se incrementa a medida que éste se "enriquece". Además, este aumento se acentúa por el envejecimiento de la población, que conlleva una mayor tasa de dependencia. Estas circunstancias, unidas a los problemas presupuestarios en numerosas economías avanzadas, llevan a la adopción de medidas de contención del gasto sanitario, como las que teóricamente justifican la necesidad de emprender reformas sanitarias. 
Algunas de dichas medidas intervienen en la demanda -trasladando una parte del coste de los servicios sanitarios al paciente- y otras en la oferta -priorizando prestaciones, cambiando los incentivos a los proveedores, protocolizando e incluso repensando todo el sistema para que se adapte a las nuevas necesidades demográficas-. Una tercera vía son los seguros sanitarios, con el riesgo de que los pacientes totalmente asegurados sean menos cuidadosos con su salud, o que consuman en exceso los servicios de salud dado que no tienen coste.

La justificación del copago estriba pues, bajo esta hipótesis, en contribuir a racionalizar el uso de los servicios que son consumidos en exceso, además de colaborar al aumento de la recaudación para financiar el sistema sanitario. Esta concepción centra el interés en analizar el impacto del copago en aquellos servicios sanitarios donde las decisiones del paciente influyan directamente en su utilización. El sistema de copago debe además tener en cuenta la renta y las necesidades de la población para proteger a los sectores más vulnerables, como los pacientes de alto riesgo (enfermos crónicos) y a las personas con rentas más bajas.

El copago farmacéutico se introdujo generalizadamente en 1978 para los usuarios de la Seguridad Social menores de 65 años; inicialmente ascendía al $20 \%$ del precio real de venta al público de los medicamentos recetados, un porcentaje que se incrementó hasta el $30 \%$ en 1979 y el $40 \%$ en 1980. La última reforma sanitaria ha vuelto a modificar estos porcentajes en atención a los criterios ya mencionados en el epígrafe 2.1 .

Las implicaciones del copago como mecanismo para promover el bueno uso de los servicios sanitarios por parte del paciente y no como forma de recaudación -si se considera como un nuevo impuesto ya pagado o co-repago (Benach, Tarafa y Muntaner, 2012)- comportan analizarlo cuando recae sobre los servicios de decisión, como las visitas a urgencias o al médico de familia y el consumo de medicamentos, concluyendo, entre otros, los siguientes aspectos (Mas et al., 2011):
- Supone una reducción en la utilización de los servicios sanitarios.

- A priori, parece no traducirse en un peor estado de salud de la población, salvo en el caso de pacientes con rentas más bajas y poblaciones de alto riesgo (como pacientes crónicos).

- La demanda es más sensible al precio en el caso de los servicios preventivos que en el caso de enfermedades agudas, es decir, los pacientes no reaccionan de la misma manera en todos los servicios.

- El diseño del copago en medicamentes no puede ser independiente de la capacidad económica del ciudadano.

Los sistemas de copago están muy extendidos en Europa, y casi todos los países europeos tienen establecidas políticas de participación del usuario en algún nivel asistencial. Sólo España, Dinamarca y Reino Unido no han extendido esta participación más allá de los fármacos (véase Cuadro1).

En Europa, los sistemas de copago tienen tanto finalidad disuasoria (sistemas donde el paciente puede decidir, como son atención primaria, servicios de urgencias y fármacos) como recaudatoria (visita a médicos especialistas y atención hospitalaria).

En cuanto al tipo de servicios afectados por los sistemas de copago, los mecanismos de contribución son variados. Algunos países aplican una tarifa única en atención primaria, con importes que van desde los mínimos de Portugal hasta los máximos de Noruega, si bien se consideran también niveles diferentes según el tipo de paciente. En otros países, por el contrario, el contribuyente paga un porcentaje del coste de la visita médica, como es el caso de Bélgica, Luxemburgo o Francia.

En la atención hospitalaria, en algunos casos se aplica el copago por día de hospitalización (Austria o Bélgica), en otros el copago es proporcional al coste total de hospitalización (Noruega) y en Francia se combinan ambas opciones. 
Una de las medidas que genera más controversia es el sistema de copago en los servicios de urgencias, aunque cada vez se extiende más por Europa. Varios países aplican la política de devolver el dinero pagado en caso de tratarse de una visita de urgencia (Grecia, Italia).

\section{Cuadro 1}

Sistemas de copago sanitario en Europa

\begin{tabular}{|l|c|c|c|c|c|}
\hline \multicolumn{1}{|c|}{ País } & $\begin{array}{c}\text { Atención } \\
\text { primaria }\end{array}$ & Especialistas & $\begin{array}{c}\text { Atención } \\
\text { hospitalaria }\end{array}$ & $\begin{array}{c}\text { Servicios de } \\
\text { urgencia }\end{array}$ & Fármacos \\
\hline Alemania & $\mathrm{X}$ & $\mathrm{X}$ & $\mathrm{X}$ & $\mathrm{X}$ & $\mathrm{X}$ \\
\hline Austria & $\mathrm{X}$ & $\mathrm{X}$ & $\mathrm{X}$ & $\mathrm{X}$ & $\mathrm{X}$ \\
\hline Bélgica & $\mathrm{X}$ & $\mathrm{X}$ & $\mathrm{X}$ & $\mathrm{X}$ & $\mathrm{X}$ \\
\hline Dinamarca & $\mathrm{NO}$ & $\mathrm{NO}$ & $\mathrm{NO}$ & $\mathrm{NO}$ & $\mathrm{X}$ \\
\hline España & $\mathrm{NO}$ & $\mathrm{NO}$ & $\mathrm{NO}$ & $\mathrm{NO}$ & $\mathrm{X}$ \\
\hline Finlandia & $\mathrm{X}$ & $\mathrm{X}$ & $\mathrm{X}$ & $\mathrm{X}$ & $\mathrm{X}$ \\
\hline Francia & $\mathrm{X}$ & $\mathrm{X}$ & $\mathrm{X}$ & $\mathrm{X}$ & $\mathrm{X}$ \\
\hline Grecia & $\mathrm{NO}$ & $\mathrm{NO}$ & $\mathrm{X}$ & $\mathrm{X}$ & $\mathrm{X}$ \\
\hline Holanda & $\mathrm{NO}$ & $\mathrm{X}$ & $\mathrm{X}$ & $\mathrm{X}$ & $\mathrm{X}$ \\
\hline Irlanda & $\mathrm{NO}$ & $\mathrm{NO}$ & $\mathrm{X}$ & $\mathrm{X}$ & $\mathrm{X}$ \\
\hline Italia & $\mathrm{NO}$ & $\mathrm{X}$ & $\mathrm{X}$ & $\mathrm{X}$ & $\mathrm{X}$ \\
\hline Luxemburgo & $\mathrm{X}$ & $\mathrm{X}$ & $\mathrm{X}$ & $\mathrm{NO}$ & $\mathrm{X}$ \\
\hline Noruega & $\mathrm{X}$ & $\mathrm{X}$ & $\mathrm{X}$ & $\mathrm{X}$ & $\mathrm{X}$ \\
\hline Portugal & $\mathrm{X}$ & $\mathrm{X}$ & $\mathrm{NO}$ & $\mathrm{X}$ & $\mathrm{X}$ \\
\hline Reino Unido & $\mathrm{NO}$ & $\mathrm{NO}$ & $\mathrm{NO}$ & $\mathrm{NO}$ & $\mathrm{X}$ \\
\hline Suecia & $\mathrm{X}$ & $\mathrm{X}$ & $\mathrm{X}$ & $\mathrm{X}$ & $\mathrm{X}$ \\
\hline
\end{tabular}

En los sistemas de copago europeos también es generalizado el uso de mecanismos de protección de los colectivos más vulnerables -pacientes con rentas más bajas y pacientes de alto riesgo- como la fijación de un límite máximo de contribución al año o la exención total.

En el caso español, y tras la última reforma, la introducción del copago en el colectivo de pensionistas y su incremento en los "activos" pretende disuadir a los usuarios de consumos excesivos o innecesarios (López Saludas, 2012), con el objetivo último de actuar como elemento recaudador para financiar el coste sanitario y farmacéutico.

\subsection{Gasto famacéutico}

La Tabla 2 resume algunos de los principales indicadores sobre el gasto farmacéutico en España y su evolución en los últimos años.
Como se observa en la Tabla, el gasto farmacéutico en recetas y el gasto en farmacia hospitalaria ha representado en la pasada década respectivamente alrededor del $23 \%$ y el $5,2 \%$ del gasto sanitario público en el promedio 1999-2005, totalizando para el gasto en medicamentos más de un $28 \%$ respecto al gasto sanitario público.

En cuanto al precio del medicamento, la OCDE señala que el precio en España era en 2005 un $77 \%$ de la media geométrica de los países OCDE. El importante volumen de ventas de medicamentos coloca en 2008 a España como el séptimo mercado farmacéutico mundial y el quinto europeo. Sin embargo, el empleo generado por la industria farmacéutica en España representó el 6,4\% del generado en Europa y la inversión en $I+D$ de la industria farmacéutica en España supuso el $3,4 \%$ de la inversión en I+D que dicha industria hizo en Europa en 2008. 
Tabla 2

Gasto farmacéutico (1999-2005)

\begin{tabular}{|c|c|c|c|c|c|c|c|}
\hline & $\mathbf{1 9 9 9}$ & $\mathbf{2 0 0 0}$ & $\mathbf{2 0 0 1}$ & $\mathbf{2 0 0 2}$ & $\mathbf{2 0 0 3}$ & $\mathbf{2 0 0 4}$ & $\mathbf{2 0 0 5}$ \\
\hline $\begin{array}{c}\text { Productos, recetas y } \\
\text { farmacia } \\
\text { hospitalaria (miles } € \text { ) } \\
\text { Farmacia recetas } \\
\text { médicas }\end{array}$ & & & & & & & \\
$\begin{array}{c}\text { Farmacia hospitalaria } \\
\text { Total gasto sector }\end{array}$ & 1.164 .490 & 1.361 .063 & 1.544 .151 & 1.834 .020 & 2.119 .507 & 2.435 .963 & 2.808 .067 \\
CC.AA. & 27.284 .460 & 29.615 .697 & 31.726 .580 & 34.592 .600 & 38.578 .408 & 41.811 .352 & 45.618 .384 \\
$\%$ Recetas/ Total PF & 84,23 & 83,33 & 82,63 & 81,43 & 80,97 & 79,81 & 78,48 \\
\hline \% sobre gasto total & & & & & & & \\
Farmacia recetas & & & & & & & \\
médicas & 22,79 & 22,97 & 23,16 & 23,25 & 23,37 & 23,04 & 22,45 \\
$\begin{array}{c}\text { Farmacia hospitalaria } \\
\text { Total productos }\end{array}$ & 4,27 & 4,6 & 4,87 & 5,3 & 5,49 & 5,83 & 6,16 \\
farmacéuticos & 27,06 & 27,57 & 28,03 & 28,56 & 28,86 & 28,86 & 28,6 \\
\hline
\end{tabular}

Fuente: Informe del grupo de trabajo de análisis del gasto sanitario (2007).

La proporción del gasto total en medicamentos financiado públicamente en España es superior al promedio europeo, especialmente desde mediados de los 90 y en progresivo aumento hasta superar en un $20 \%$ el promedio europeo en 2007 (Simó Miñana, 2011).

En cuanto a la evolución del copago y, en definitiva, la participación de los pacientes en la financiación del consumo farmacéutico público, su tendencia es decreciente en los años anteriores a la última reforma sanitaria. En los medicamentos dispensados en farmacias se redujo la tasa efectiva de copago a cargo de los pacientes (porcentaje de participación de los pacientes en el coste de los medicamentos) desde casi el $20 \%$ a comienzos de los ochenta al $6 \%$ en 2009 , siendo este porcentaje uno de los más bajos de Europa, motivado tal vez porque el sistema se plantea para activar el copago en tratamientos orientados a procesos agudos del paciente activo. En los últimos años, sin embargo, con el incremento de la esperanza de vida y de la comorbilidad, el progresivo envejecimiento poblacional español, la orientación de la industria en productos para tratamiento de procesos crónicos y la extensión de las pensiones, se modifica la situación, tal que el consumo del gasto farmacéutico público debido a los pensionistas aumenta de forma continua.

Además, en esa reducción del porcentaje efectivo de copago influyen otros factores, como el uso fraudulento de recetas mediante el trasvase de las de no pensionistas a pensionistas; sin embargo, el copago de los no pensionistas también se ha reducido desde el $36,6 \%$ en 1981 al $22 \%$ en 2009 , posiblemente por el número de medicamentos sujetos a aportación reducida sobre el total de incluidos en la financiación pública. Es previsible un aumento del número de envases de medicamentos de aportación reducida prescritos a pacientes activos en la misma cantidad en que disminuye la prescripción de envases de medicamentos de aportación normal.

Combinando toda esta información, el hecho de que los medicamentos autorizados en España tengan un precio inferior al promedio de los países europeos más desarrollados parecería llevar a que la superioridad del gasto farmacéutico respecto a Europa se deba a una mayor intensidad de uso por prescripción, dispensación o consumo. Sin embargo, los estudios no han demostrado que el consumo español de los grupos terapéuticos explique esta situación. 


\section{Gestión sanitaria}

La asistencia sanitaria pública en España durante el siglo pasado comenzó siendo marginal tanto en cobertura de población como en extensión de las prestaciones, dando cober- tura al $20 \%$ de la población en 1942 y al $45 \%$ en 1960. La ampliación de las prestaciones y el desarrollo de una creciente red de asistencia sanitaria fueron caracterizando paulatinamente los avances en gestión durante las décadas centrales (Cuadro 2).

\section{Cuadro 2}

Gestión sanitaria española en el siglo XX

\begin{tabular}{|c|l|}
\hline \multicolumn{1}{|c|}{ Fecha } & \multicolumn{1}{c|}{ Cambios en gestión sanitaria } \\
\hline Segunda República & Instituto Nacional de Previsión (INP): Ley de coordinación sanitaria \\
\hline $1942-1977$ & Ministerio de Trabajo y Seguridad Social gestiona la asistencia sanitaria de la Seguridad Social \\
\hline 1942 & $\begin{array}{l}\text { Seguro Obligatorio de Enfermedad para asistencia curativa a trabajadores de rentas bajas y sus } \\
\text { beneficiarios }\end{array}$ \\
\hline 1944 & $\begin{array}{l}\text { Ley de Bases de Sanidad Nacional. } \\
\text { Creación de la Red Sanitaria de la Seguridad Social. Apertura de ambulatorios }\end{array}$ \\
\hline 1962 & $\begin{array}{l}\text { Ley de Hospitales, con red propia de la Seguridad Social. } \\
\text { Ampliación de red de ambulatorios y consultorios }\end{array}$ \\
\hline 1974 & Ley General de la Seguridad Social: ampliación de prestaciones sanitarias \\
\hline 1977 & Dependencia del Ministerio de Sanidad y Seguridad Social \\
\hline 1978 & Medicina de familia como especialidad independiente \\
\hline 1979 & Reestructuración del INSALUD \\
\hline
\end{tabular}

Fuente: Angora Mazuecos y Salve Díaz-Miguel (2011).

En los años 60 y 70 se desarrolló una amplia red de modernos hospitales públicos, y con el comienzo de la transición se observaron problemas como el retraso de la atención primaria en comparación con la red de hospitales, la irregular distribución geográfica de las estructuras y recursos sanitarios, y la persistencia de grandes desigualdades entre los más necesitados (con acceso restringido a la beneficencia), el gran grupo de trabajadores asalariados (cubiertos por la Seguridad social) y las clases altas (atendidas en el sistema privado, especialmente en los casos de atención primaria y preventiva).

Desde 1977 el Ministerio de Sanidad y Seguridad Social descentralizó las tareas administrativas, extinguiendo el INP, cuyas funciones pasaron a tres institutos: Instituto Nacional de la Seguridad
Social, Instituto de Servicios Sociales e Instituto Nacional de la Salud (INSALUD), siendo éste último reestructurado en 1979. En 1985, el INSALUD implantó las direcciones médica, de enfermería y de servicios generales.

La descentralización iniciada en los 80 se produjo de forma progresiva. Todas las CC.AA tenían ya responsabilidad en las redes públicas de la asistencia sanitaria de ámbito local (sistema de beneficencia, redes de vigilancia y tratamiento de enfermedades infecciosas, prevención y promoción de la salud, red de asistencia primaria rural, etc.) que podrían denominarse como redes anteriores al Sistema de la Seguridad Social, y su gestión fue el germen de los servicios regionales de salud 
creados por cada administración regional (García Armesto et al., 2010).

La ley 15/1997, de habilitación de nuevas formas de gestión, recogió gran parte de las recomendaciones del "Informe Abril" de 1991", que ya propugnaba mejorar la eficiencia de los centros y del SNS. A raíz de esta normativa, han proliferado nuevos modelos de gestión, principalmente en determinadas CC.AA., bajo fórmulas variopintas: fundaciones sanitarias, concesiones administrativas, consorcios, iniciativas de financiación privada, organizaciones sanitarias integradas, entidades de base asociativa, empresas públicas, institutos, etc.

La Ley General de Sanidad otorgó a las CC.AA. la responsabilidad exclusiva de la organización de sus servicios de salud, creando progresivamente una estructura fuertemente descentralizada de organización y gasto sanitario que se inició en 1983 con la creación del Servicio Vasco de Salud y concluyó en 2001 con el caso de Cantabria.

Por su parte, la Ley 16/2003 de Cohesión y calidad del SNS definió seis ámbitos de colaboración entre el Estado y las CC.AA.: prestaciones del sistema, farmacia, profesionales, investigación, sistema de información y calidad. Precisamente en uno de ellos, la política de recursos humanos, se produce uno de los principales problemas de coordinación entre Estado y Comunidades, manifestándose en aspectos como las políticas retributivas, el desarrollo de la carrera profesional, los desajustes en la oferta y demanda de profesionales médicos y de enfermería y la movilidad de los mismos. En cuanto al primero, la culminación en 2002 del proceso de transferencias del INSALUD a las CC.AA. generó una dinámica inflacionista en las rentas salariales del sector.

\footnotetext{
2 Informe presentado como proposición no de Ley por la que se instaba al Gobierno a la constitución de una Comisión para la revisión del Sistema Nacional de Salud y las tendencias de su entorno en ese momento y cara al futuro. El presidente de la Comisión encargada de su elaboración era Vicente Abril Martoreu.
}

En materia de competencias, el Ministerio de Sanidad, Servicios Sociales e Igualdad (antes Ministerio de Sanidad y Política Social) se encarga de la legislación en materia farmacéutica $y$ es el garante del funcionamiento equitativo de los servicios sanitarios en todo el país. Le corresponde asimismo la función central de coordinación de un SNS repartido en 17 sistemas sanitarios regionales, que únicamente rinden cuentas ante sus parlamentos regionales. El resultado es que la negociación, el consenso y la financiación finalista adicional son factores fundamentales de las políticas del SNS y que el diálogo se produce en el CISNS (Consejo Interterritorial del Sistema Nacional de Salud).

Desde 2009 se ha otorgado al Ministerio de Sanidad la responsabilidad de la política social, con el mandato de poner en marcha el nuevo Sistema para la Autonomía y Atención a la Dependencia (SAAD).

Además, tras un período de gran confrontación política, el Pacto por la Sanidad de 2008 identifica qué materias del SNS deben regirse por el consenso: recursos humanos, cartera de servicios sanitarios comunes ${ }^{3}$, acreditación de servicios y centros de referencia nacionales, necesidades de financiación, salud pública (incluyendo el calendario de vacunas), tiempos máximos de espera, política sobre drogodependencia, calidad e innovación.

Por último, no puede olvidarse el importante papel de las compañías de seguros en la atención de accidentes de trabajo y enfermedades profesionales. Estas contingencias están cubiertas por mutualidades que financia la tesorería nacional de la Seguridad Social, principalmente mediante contribuciones de los empleadores.

\footnotetext{
3 La cartera de servicios del SNS fue definida por primera vez en 1995 con el objetivo de consolidar todos los servicios existentes como servicios básicos -de prestación obligatoria para las CC.AA.-. El resultado fue que sólo excluía la atención dental para los adultos y parcialmente la asistencia sociosanitaria.
} 
Hasta 1996, los servicios de salud laboral se gestionaban a través de los propios fondos mutualistas de la Seguridad Social, o directamente a través del SNS. Desde entonces, esos servicios se han concertado progresivamente con entidades privadas sin ánimo de lucro, que también están capacitadas para gestionar las bajas por enfermedad correspondientes. En el sistema actual, el SNS y las mutualidades se encargan de la incapacidad temporal por causas ordinarias, pero cuando se debe a la actividad profesional de una persona o un accidente laboral, estas mutuas se hacen cargo de la prestación de asistencia sanitaria y rehabilitación necesarias, así como de la gestión de la transferencia de fondos que debe realizarse al trabajador para cubrir su periodo de incapacidad.

\section{Actualidad y últimas reformas}

El Barómetro Sanitario de 2011 valora con un 6,59 sobre 10 al sistema sanitario público e indica que para el $48,9 \%$ de los españoles el sistema sanitario funciona bien, aunque son necesarios algunos cambios (CIS, 2011). Además, entre las medidas de control de gasto sanitario, los encuestados valoran como la más eficiente $(8,53)$ la ampliación de medios en los centros de salud para que los médicos de familia puedan resolver más problemas, seguida por proporcionar las dosis justas de medicamento a cada paciente $(8,33)^{4}$.

En el marco político, las últimas reformas parecen cuestionar los tradicionales principios de universalidad, solidaridad y equidad que hasta hace poco venían caracterizando nuestro sistema sanitario, centrando el debate en cuestiones como el ya mencionado copago o el trasvase de la gestión pública a la privada para los servicios sanitarios públicos, como el programa de privatización de la gestión de seis hospitales públicos en Madrid.

\footnotetext{
4 Para un completo análisis de la percepción de los ciudadanos sobre el sistema sanitario, consúltese también Jurado (2012).
}

En la reforma sanitaria las dos alternativas de privatización, en la teórica búsqueda de mayor eficiencia y menor coste en la prestación de este servicio público, son de carácter formal -gestión directa a través de entidades de titularidad pública sometidas a derecho privadoo funcional -gestión indirecta mediante entidades privadas a través de contratos-. En cualquier caso, se trata de implantar un modelo empresarial para la gestión sanitaria y separar, por un lado, las funciones de financiación y compra de los servicios sanitarios y, por otro, las de gestión y producción de éstos, fomentando así la competencia entre proveedores.

El desarrollo de formas de contratación externa o gestión indirecta de la atención sanitaria pública con proveedores privados comerciales, mediante fórmulas de "concesión administrativa" de atención a toda la población de una área de salud es una de las estrategias llevadas a cabo en los últimos años. Este modelo, aplicado en Valencia y Madrid, es un ejemplo de partenariado público privado (PPP o Public Private Partnership) que transfiere mediante concesión también los servicios médicos, y no sólo la construcción, instalaciones, mantenimiento y servicios generales, que es lo incluido por el sistema británico de PE (también denominado PFI o Private Finance Initiative). En España estas concesiones administrativas se conocen como "modelo Alzira" (véase 2.1) y es una fórmula de gestión indirecta por la que la empresa concesionaria recibe de la Comunidad Autónoma un pago (canon) durante todo el período de vigencia de la concesión (generalmente 30 años).

En cualquier caso, los estudios no evidencian que la gestión privada sea más eficiente que la pública, entre otros motivos, porque no se producen verdaderas reducciones en el coste ni se transfieren realmente riesgos al sector privado (Sánchez, Abellán y Oliva, 2013). Así, en un trabajo aplicado al caso de la Comunidad Valenciana, no se observan diferencias significativas en el gasto hospitalario por habitante comparando áreas de gestión directa y áreas de gestión privada por concesión (Peiró y 
Meneu, 2012). A nivel internacional, las fórmulas $\mathrm{PFI}$ antes citadas para la construcción de hospitales pueden suponer un coste total superior al que resultaría de acudir al endeudamiento público para construir la infraestructura necesaria (Barlow et al., 2013).

La crisis económica ha disparado el proceso de reformas y ha acentuado el debate sobre la sostenibilidad del SNS, para cuya garantía pueden perfilarse dos estrategias: aumentar los ingresos fiscales dedicados a esta finalidad, o aumentar la eficiencia del sistema de provisión sanitaria. En cuanto a la primera, frente a los sistemas de copago sanitario, desde el punto de vista de la eficiencia es preferible usar impuestos finalistas, creando un fondo que se nutra de dichos recursos y permita financiar políticas de corrección de desigualdades y de lucha contra causantes de morbi-mortalidad (enfermedades cardiovasculares, cáncer, diabetes, etc.). Respecto al aumento de la eficiencia, debe mejorarse la gobernanza del sistema (desarrollando un código de buen gobierno del SNS), desarrollar un sistema de información integral del SNS, desarrollar una política estratégica integrada de salud pública a nivel estatal que impida rupturas unilaterales de una Comunidad Autónica sobre aspectos que generen externalidades negativas en poblaciones de otras CCAA, protocolizar la atención sanitaria mediante guías clínicas a nivel nacional, y llegar a un acuerdo sobre políticas de RR.HH. a nivel estatal junto a un pacto de rentas. Por todo ello, es posible cuestionar la generalizada idea sobre el bajo coste de nuestro sistema sanitario (López Casanovas, 2010).

La publicación del Real Decreto-ley 16/2012, de 20 de abril, de medidas urgentes para garantizar la sostenibilidad del SNS refleja la (pen)última estocada en la línea de recortes en la prestación sanitaria empezando por defender un nuevo concepto de población asegurada que lucha frontalmente contra la concepción universal del sistema sanitario español. Estas medidas han venido acompañadas por otras adoptadas desde algunas CC.AA., que parecen responsabilizar al sistema sanitario español de sus déficits, respondiendo a esta situación con notables recortes en personal, cierre o limitación de uso en instalaciones, reducción de prestaciones básicas e implantación de copagos. Todas estas actuaciones se justifican a partir de una supuesta insuficiencia crónica de la financiación pública de la atención sanitaria.

En el caso español, además, las empresas privadas de seguros sanitarios han tenido, hasta ahora, un desarrollo limitado, circunstancia compartida por aquellos países con SNS. Actualmente, son precisamente estos países los más presionados para afrontar reformas estructurales que faciliten la entrada de aseguradores privados. Este elemento, junto con el incuestionable poder de la industria farmacéutica, explican también los cambios producidos en los servicios sanitarios de muchos estados, subrayados además por la crisis económica (Rey del Castillo, 2012). Las actuales exigencias de los mercados financieros de una política de consolidación fiscal dibujan un horizonte de pérdida de rentas de los profesionales del sector sanitario público, unido a una previsible destrucción de puestos de trabajo.

Junto a estos elementos económicos, otros factores estructurales del sistema sanitario español ponen también en cuestión su futuro: la existencia de distintos sistemas de cobertura sanitaria (mutualidades de funcionarios), la presencia de un sistema descentralizado y sin coordinación adecuada, los problemas del sistema de financiación autonómico, la diversificación de las formas de gestión de los servicios sanitarios en distintas CC.AA., etc.

En los datos comparados de gasto sanitario ofrecidos por la OCDE se observa, como se ha mencionado anteriormente, que a partir de cierto nivel de renta, cuanto mayor es el de un país, mayor es la proporción de gasto público sobre el gasto sanitario total. Además, a medida que aumenta el nivel de renta per cápita de un país, es menor la proporción de gasto sanitario financiado de manera individual (incluyendo tasas y copagos), o dicho de otro 
modo, cuanto mayor el nivel de renta menor la financiación privada de la atención sanitaria (Evans, 2007). Estos resultados parecen contradecir la eficacia y, sobre todo, motivación del traslado hacia la gestión privada y medidas de co-pago que presiden la actualidad española.

Adicionalmente, en otros países con SNS - casos de Reino Unido o Canadá- se impone la ausencia de copagos o tasas de acceso a los servicios (excluyendo pues el pago de medicamentos), a fin de garantizar el igual acceso a los mismos con independencia del nivel de renta.

\section{E sistema sanitario en la provincia de León (1986-2011)}

En 2010 2.474.584 personas estaban cubiertas por el Sistema Nacional de Salud en Castilla y León, correspondiendo el $19,33 \%$ a la provincia de León.

En el ámbito normativo, la transferencia de competencias del SNS se materializa, en el caso de Castilla y León, con la aprobación en 1983 de su Estatuto de autonomía (Ley Orgánica 4/1983, de 25 de febrero), que supone la transferencia en competencias de Sanidad e Higiene, Promoción, Prevención y Restauración de la Salud. Después de otras modificaciones legislativas, la Ley de Ordenación del Sistema Sanitario de Castilla y León (Ley 1/1993, de 6 de abril) determina el Sistema de Salud de Castilla y León y la Gerencia Regional de Salud. Otro punto clave es el traspaso a la Comunidad de Castilla y León de las funciones y servicios del Instituto Nacional de Salud en materia de gestión de la asistencia sanitaria de la Seguridad Social (RD 1480/2001, de 27 de diciembre, efectivo a partir del 1 de enero de 2002).
Para el análisis empírico del sistema sanitario en la provincia de León se han tenido en cuenta dos aspectos fundamentales e inevitablemente interrelacionados: la disponibilidad de datos y los indicadores clave del Sistema Nacional de Salud. La información se ofrece habitualmente a nivel autonómico, lo que dificulta obtener datos a nivel provincial, especialmente en el caso de cifras muy desagregadas o de datos poco recientes. En cuanto al segundo aspecto, resulta necesario incluir en el análisis, al menos, indicadores sobre establecimientos sanitarios (número de hospitales), dotación instalada (número de camas), recursos humanos (personal sanitario colegiado) y actividad asistencial en régimen hospitalario (estancias en hospitales y pacientes dados de alta).

\subsection{Recursos, dotación sanitaria y actividad}

Los datos considerados en esta parte inicial corresponden a establecimientos sanitarios en régimen cerrado, esto es, centros sanitarios que tienen como finalidad principal la prestación de asistencia médica, quirúrgica o médico-quirúrgica a los enfermos en ellos ingresados, y no a establecimientos en régimen abierto (ambulatorio, consultorio, centro de salud), dado que la información desglosada sobre estos últimos sólo es accesible para algunos años.

Comenzando por los hospitales, considerados como todo centro sanitario destinado a la asistencia especializada y continuada de pacientes en régimen de internado, cuya finalidad principal es el diagnóstico y/o tratamiento de los enfermos allí ingresados, así como la atención a pacientes de forma ambulatoria, el Gráfico 1 muestra que en el momento inicial del estudio (1986), en León había 19 hospitales, frente a los 10 que permanecen en 2009; por tanto, se ha producido un descenso del 47,37\%. En el caso de la Comunidad Autónoma de Castilla y León, el descenso en el número de hospitales en el período analizado es del 39,39\% (de 66 a 40). 


\section{Gráfico 1}

Número de hospitales

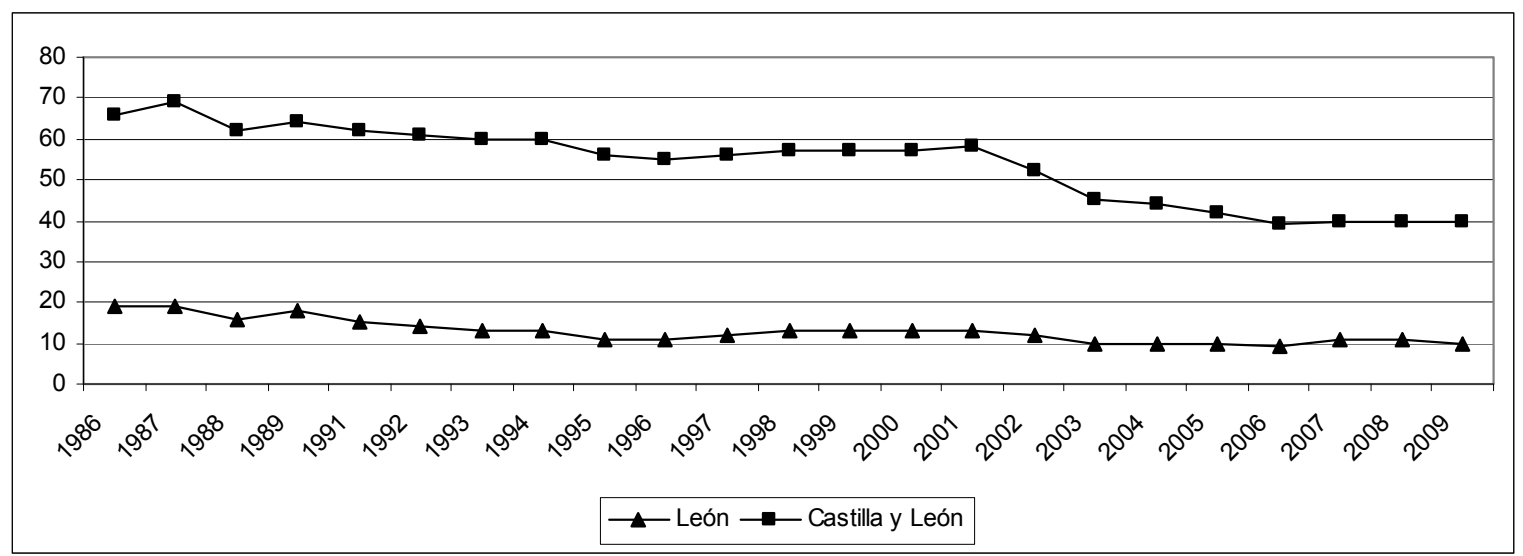

Fuente: Elaboración propia

Nota: Los datos de 1990 no están disponibles ni en la Dirección General de Estadística de la Junta de Castilla y León ni en el INE gratuitamente.

Durante estos 25 años, es interesante además comprobar la evolución en términos de distribución de hospitales según su finalidad asistencial (Gráfico 2), es decir, aquella actividad asistencial a la que el centro dedique la mayor parte de sus recursos, tanto humanos como de equipamiento: general, quirúrgico, psiquiátrico, geriatría o larga estancia, y otros. Se considera hospital general el destinado a la atención de pacientes afectos de patología variada y que atiende las áreas de medicina, cirugía, obstetricia y ginecología, y pediatría. También se considera general cuando, aún faltando o estando poco desarrollada alguna de esas áreas, no concentre la actividad asistencial en una determinada área.

\section{Gráfico 2}

\section{Hospitales según finalidad asistencial}

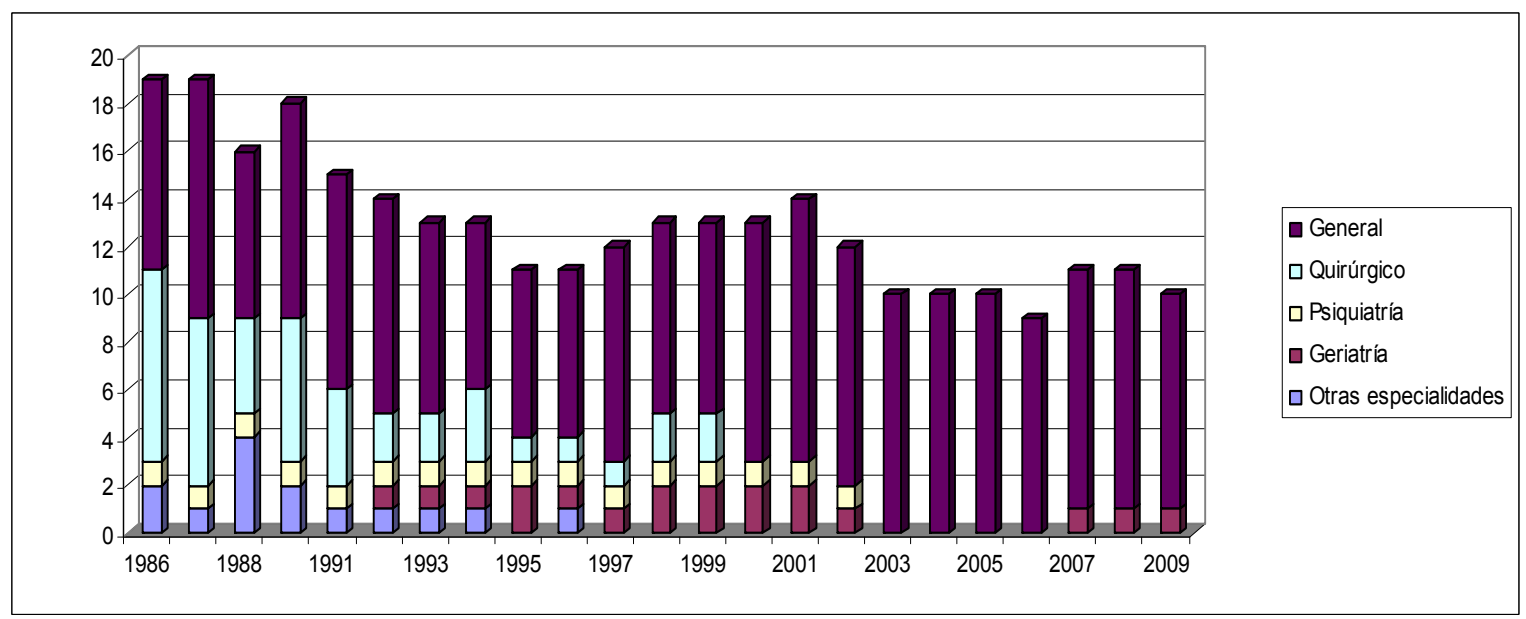

Fuente: Elaboración propia. 
Del Gráfico se desprende que siempre han predominado los hospitales generales, siendo ésta la naturaleza de todos los centros sanitarios de la provincia entre 2003 y 2006. Además, se ha tendido a una concentración de especialidades en determinadas provincias de la Comunidad Autónoma. Así, frente a los 8 hospitales quirúrgicos con que contaba la provincia de León en 1986 (el 44,44\% del total hospitalario) se ha pasado a la casi desaparición de toda especialización a partir del año 2002. Esta tendencia se observa también a nivel autonómico: en 2009, por ejemplo, 32 de los 40 hospitales de Castilla y León son generales.
El otro aspecto relevante sobre el número de hospitales es su dependencia patrimonial y/o funcional (Gráfico 3). El interés se centra en este punto en la persona física o jurídica propietaria, al menos, del inmueble ocupado por el centro sanitario, en el primer caso, o quién gestiona el centro en el segundo. Los hospitales bajo la dependencia de la Seguridad Social pertenecen a la Tesorería General de la Seguridad Social y los establecimientos hospitalarios asumidos por las Comunidades Autónomas tienen transferidos los servicios y funciones del INSALUD en el SNS.

\section{Gráfico 3}

\section{Hospitales según dependencia patrimonial}

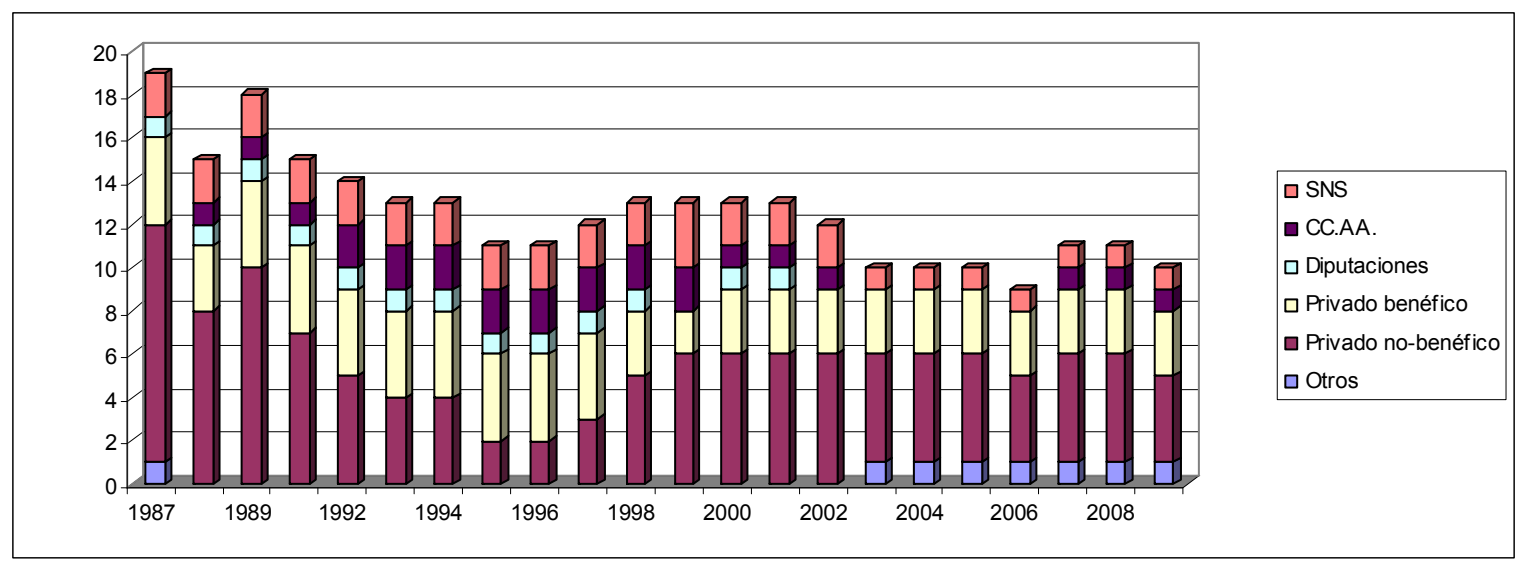

Fuente: Elaboración propia.

El número de camas instaladas es otro indicador destacado sobre los recursos sanitarios, considerando las que constituyen la dotación fija del hospital y están en disposición de ser usadas $^{5}$. En el período analizado se ha producido una progresiva disminución del número de camas instaladas, si bien su reducción es inferior porcentualmente a la producida en hospitales. Así, los hospitales de

\footnotetext{
5 No se incluyen las camas destinadas a observación en el servicio de urgencias, las de acompañantes, personal del establecimiento sanitario, empleadas para hemodiálisis ambulatoria o exploraciones especiales, ni cunas de recién nacidos sanos.
}

León disponen de 19,23\% menos camas al final del período considerado, habiéndose alcanzado el máximo en 1986 (2.647 camas) y el mínimo en 2006 (2.128). Igualmente, en Castilla y León el descenso en el período 1986-2009 es del $35,76 \%$.

De la combinación de los dos datos anteriores puede obtenerse la ratio de número de camas/hospital, que permite además establecer comparaciones de la provincia de León con la Comunidad Autónoma y también con España, al menos para los años con disponibilidad de información. Que la disminución en el número de camas instaladas no sea tan elevada como 
el decremento en el número de hospitales explica que la ratio calculada para Castilla y León y para la provincia de León haya ido en aumento en los últimos años (al menos hasta 2006). En 2009, las cifras de León $(213,80$ camas/hospital) se sitúan por debajo de la media de la Comunidad Autónoma $(239,47)$ pero superando a la media española $(200,85)$.
Otro indicador clave sobre los recursos sanitarios muestra la relación entre camas hospitalarias y población (Gráfico 4): León se sitúa desde 1996 por encima de la media de la Comunidad Autónoma y de España, alcanzando el máximo de 0,00469 camas/ habitante en 2002. En 2008 esa media es de 0,00432 en León, 0,00372 en Castilla y León y 0,00349 en España.

\section{Gráfico 4}

\section{Ratio Camas/Población}

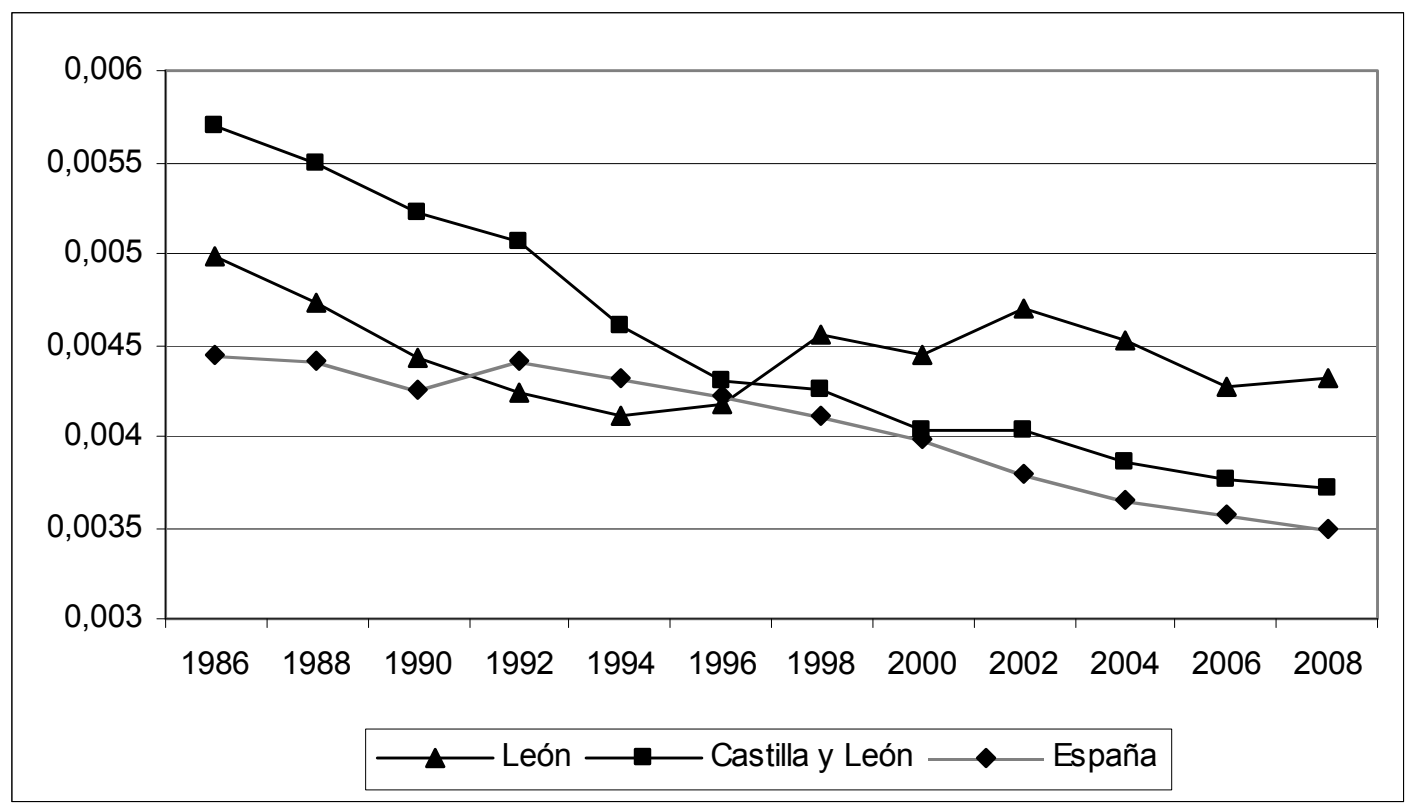

Fuente: Elaboración propia.

En términos de actividad y de capacidad de atención sanitaria prestada por los centros hospitalarios, es interesante la evolución del censo de enfermos hospitalizados, considerando "enfermo" a toda persona que haya ingresado en un centro hospitalario para ser atendida, diagnosticada y observada en régimen de internado, no incluyendo a los recién nacidos. El Gráfico 5 recoge en términos absolutos esta información, y muestra una disminución, si bien no continuada, en el número de enfermos hospitalizados, desde 762.753 estancias en 1986 a las 533.107 de
2008, última cifra disponible. En Castilla y León hay 2.281.178 estancias en 2008, poco más de la mitad de los datos de 1993 (4.348.415 enfermos).

Esas estancias pueden analizarse también por género, resultando que, en el caso de León, todos los años, a excepción de 1991, 1997, 1998 y 1999 , el número de varones hospitalizados es superior al número de mujeres (Gráfico $6)$. 


\section{Gráfico 5}

Número de estancias en hospitales

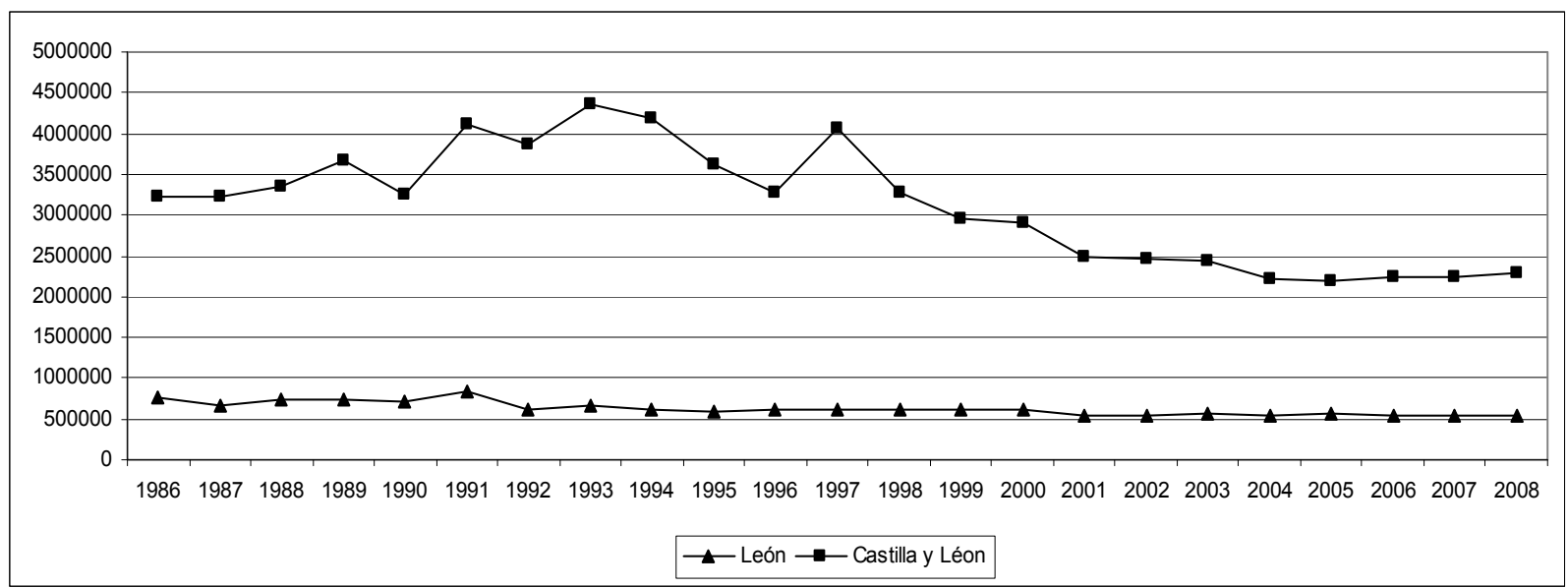

Fuente: Elaboración propia.

\section{Gráfico 6}

\section{Estancias por género (León)}

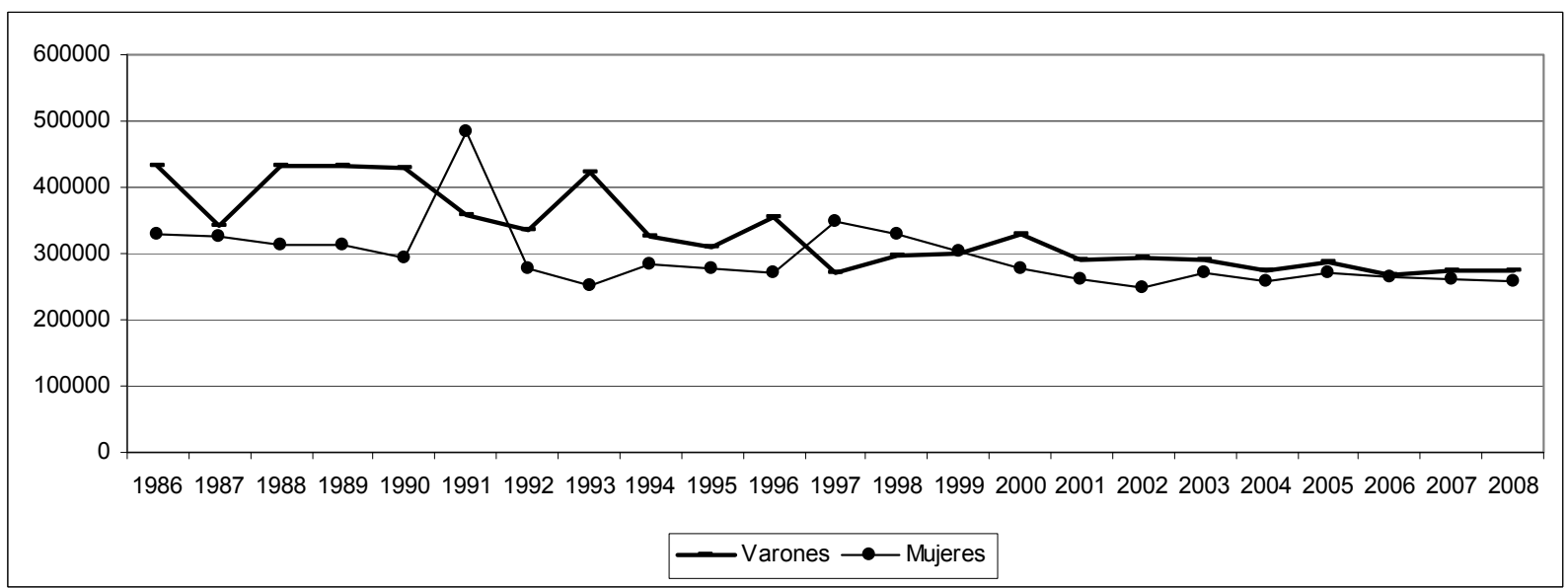

Fuente: Elaboración propia.

Continuando con la actividad sanitaria, el Gráfico 7 recoge el número de enfermos dados de alta en León, clasificados por género, en cifras que muestran un progresivo ascenso a lo largo del período de estudio. La brusca disminución de 2002 está motivada por diferencias estadísticas, debido a que desde esa fecha sólo se incluyen los datos de hospitales públicos. 


\section{Gráfico 7}

Enfermos dados de alta por género (León)

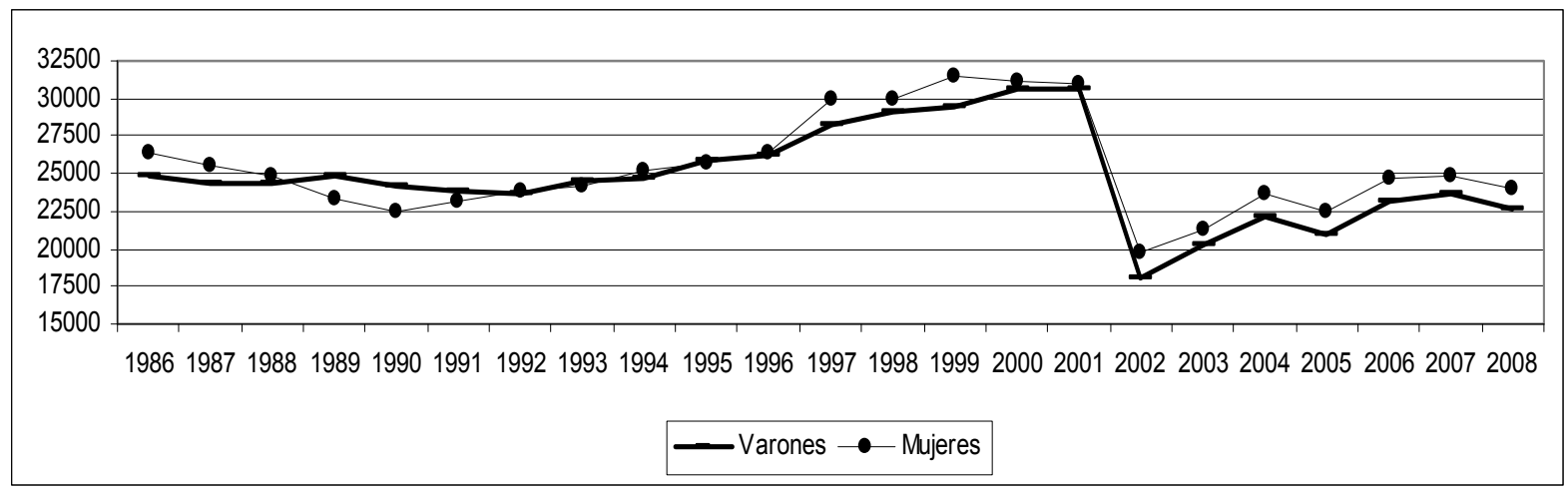

Fuente: Elaboración propia.

En términos de mortalidad, el Gráfico 8 representa las cifras por género, siendo siempre superior la tasa de mortalidad en hombres que en mujeres, aunque la diferencia se acorta particularmente en el último año de estudio (1.358 hombres más que mujeres).

\section{Gráfico 8}

\section{Mortalidad por género (León)}

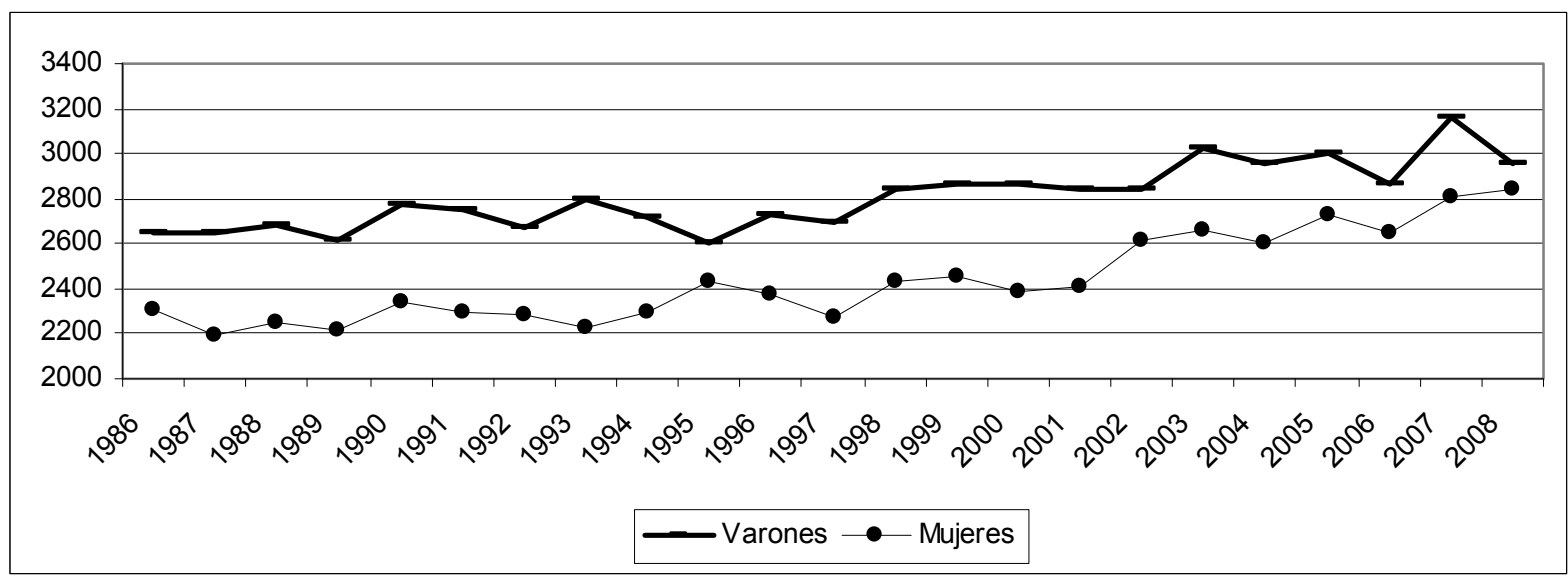

Fuente: Elaboración propia.

Por último, la Tabla 3 resume otros de los indicadores de actividad de la Comunidad en comparación con los datos nacionales. Más allá del incremento de todas las variables consi- deradas, destaca el producido en cirugías ambulatorias, que casi se duplican en ambos contextos en el período 1999-2004. 
Tabla 3

Evolución de actividad sanitaria

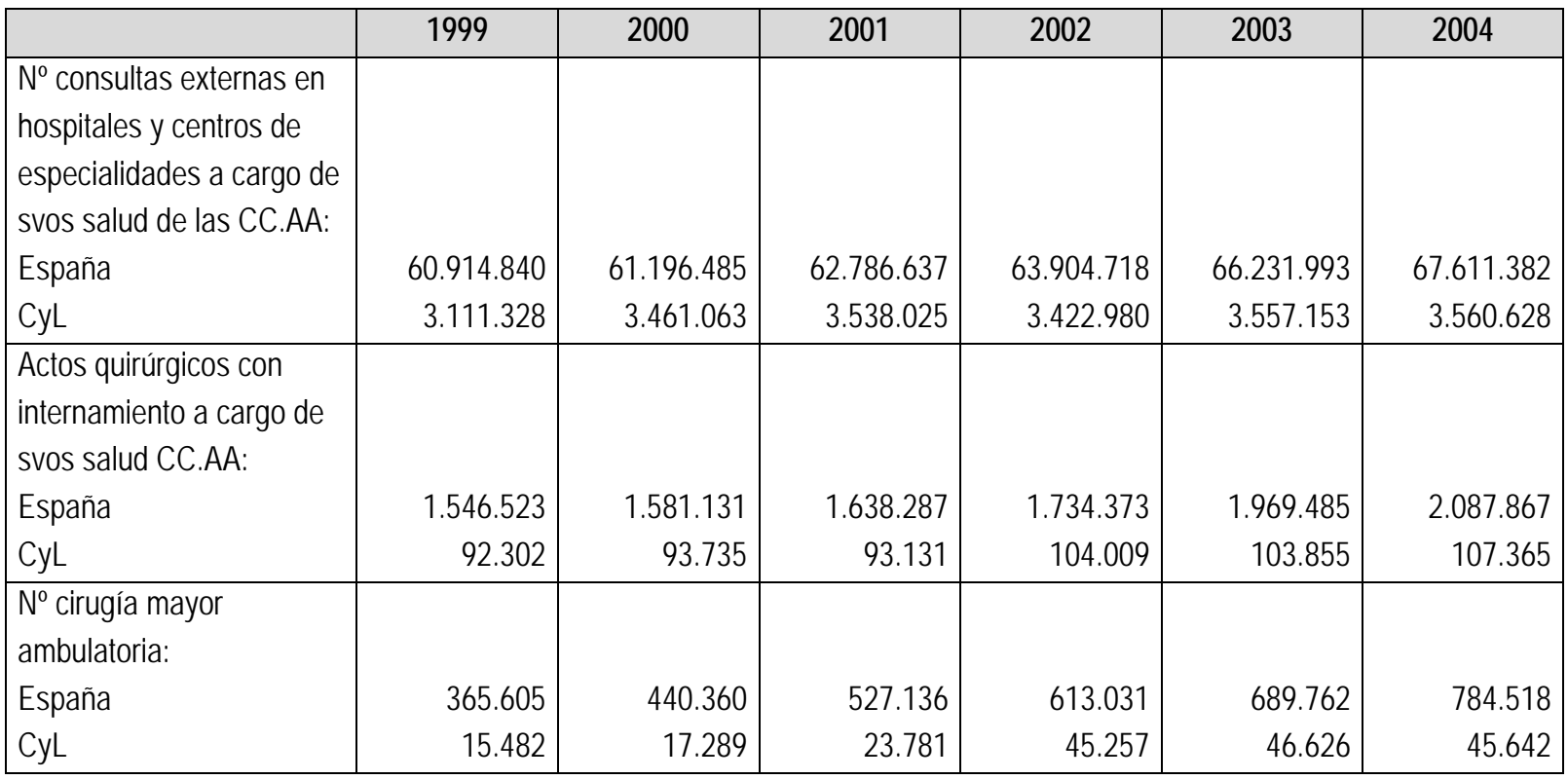

Fuente: Informe del grupo de trabajo de análisis del gasto sanitario (2007).

\subsection{Recursos humanos}

En cuanto al personal sanitario la Tabla 4 resume los datos recogidos en la Estadística de profesionales sanitarios colegiados (elaborada por el INE desde 1953 a partir de la información del Consejo General de los respectivos colegios profesionales). Atendiendo a la provincia de colegiación, se observan las siguientes cifras en el período 1997-2011 para León en términos absolutos, y a continuación se refleja el porcentaje que representan sobre el total de colegiados en Castilla y León, cifra interesante si tenemos presente que León cuenta con el $19,42 \%$ de la población de Castilla y León en 2011.

\subsection{Gasto sanitario en Castilla y León}

Si bien en el epígrafe 4 se ha hecho referencia al comportamiento global del gasto sanitario, es posible conocer las cifras para la Comunidad de Castilla y León, según el último "Informe del grupo de trabajo de análisis del gasto sanitario" publicado en 2007. Así, el Gráfico 9 recoge la importancia relativa del gasto sanitario sobre el PIB y gasto público, en comparación con los valores medios calculados para el total de CC.AA. Gráficamente se observa inicialmente el paulatino incremento del gasto sanitario sobre PIB y la disminución del peso del gasto sanitario en el gasto público total, con porcentajes particularmente elevados o reducidos, respectivamente en 2003, y cifras más estables en los años finales. 
Tabla 4

Personal sanitario colegiado

\begin{tabular}{|c|c|c|c|c|c|c|c|c|c|c|c|c|}
\hline \multirow{2}{*}{ Año } & \multicolumn{2}{|c|}{ Médicos } & \multicolumn{2}{c|}{$\begin{array}{c}\text { Odontólogos y } \\
\text { estomatólogos }\end{array}$} & \multicolumn{2}{c|}{ Farmacéuticos } & \multicolumn{2}{c|}{ Enfermería* } & \multicolumn{2}{c|}{ Podólogos $^{* *}$} & \multicolumn{2}{c|}{ Fisioterapeutas** $^{*}$} \\
\hline & León & $\%$ & León & $\%$ & León & $\%$ & León & $\%$ & León & $\%$ & León & $\%$ \\
\hline 1997 & 1.883 & 16,89 & 160 & 19,93 & 584 & 18,84 & 2.163 & 16,93 & & & & \\
\hline 1998 & 1.959 & 17,17 & 202 & 23,79 & 581 & 17,98 & 2.287 & 18,06 & & & & \\
\hline 1999 & 1.950 & 16,90 & 204 & 23,86 & 594 & 17,77 & 2.339 & 18,06 & & & & \\
\hline 2000 & 2.015 & 17,06 & 211 & 23,73 & 620 & 17,78 & 2.374 & 17,81 & & & & \\
\hline 2001 & 2.039 & 17,30 & 211 & 23,55 & 642 & 18,37 & 2.502 & 18,58 & & & & \\
\hline 2002 & 2.062 & 17,11 & 221 & 24,18 & 655 & 18,58 & 2.611 & 18,84 & & & & \\
\hline 2003 & 2.059 & 16,87 & 231 & 24,95 & 661 & 18,39 & 2.745 & 18,94 & 19 & 13,38 & & \\
\hline 2004 & 2.103 & 17,04 & 219 & 24,86 & 659 & 17,89 & 2.803 & 19,39 & 25 & 16,03 & & \\
\hline 2005 & 2.125 & 17,05 & 221 & 24,47 & 658 & 17,64 & 2.906 & 20,07 & 27 & 15,98 & & \\
\hline 2006 & 2.137 & 17,01 & 229 & 24,31 & 663 & 17,53 & 3.037 & 20,47 & 33 & 16,58 & 241 & 21,23 \\
\hline 2007 & 2.184 & 17,09 & 237 & 24,08 & 673 & 17,91 & 3.104 & 20,41 & 37 & 16,74 & 262 & 20,74 \\
\hline 2008 & 2.200 & 16,97 & 245 & 23,74 & 669 & 17,77 & 3.040 & 19,60 & 39 & 16,81 & 279 & 19,50 \\
\hline 2009 & 2.287 & 17,22 & 250 & 23,47 & 688 & 17,93 & 3.101 & 19,34 & 39 & 16,46 & 306 & 19,33 \\
\hline 2010 & 2323 & 17,19 & 258 & 23,14 & 691 & 17,94 & 3.179 & 19,38 & 39 & 16,53 & 322 & 18,96 \\
\hline 2011 & 2358 & 17,23 & 270 & 23,18 & 700 & 18,23 & 3.299 & 19,44 & 41 & 17,08 & 338 & 18,83 \\
\hline
\end{tabular}

Fuente: Elaboración propia.

*Dado que no es obligatorio estar colegiado para ejercer, las cifras pueden estar infravaloradas.

** Los datos relativos a podólogos colegiados no se conocen hasta diciembre de 2003. En el caso de fisioterapeutas, desde 2006.

\section{Gráfico 9}

\section{Gasto sanitario}

Gasto sanitario / PIB (\%)

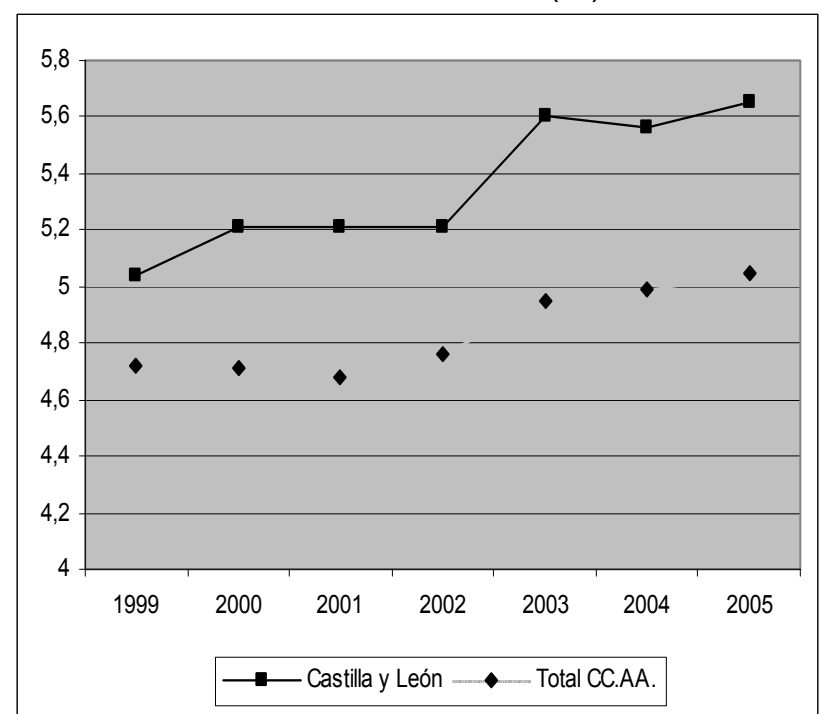

Fuente: Elaboración propia.

El Gráfico 10 resume la distribución del gasto sanitario de la comunidad siguiendo una clasificación funcional. En todos los años aproximadamente el $50 \%$ se debe a servicios
Gasto sanitario / Gasto público (\%)

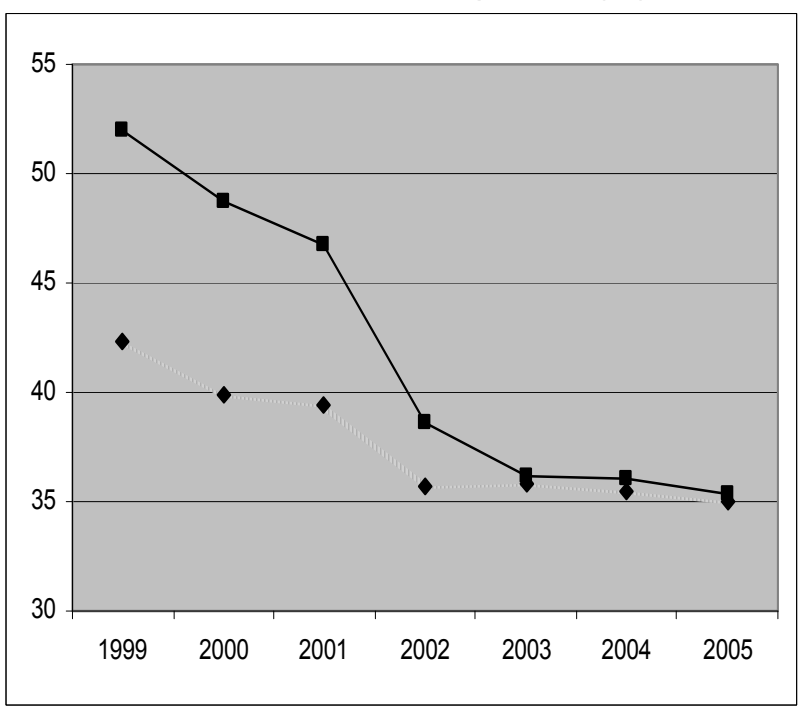

hospitalarios y especializados, seguidos por el gasto en farmacia (recetas), en cifras similares a las del total nacional ya referido. 


\section{Gráfico 10}

\section{Distribución del gasto sanitario (Castilla y León)}

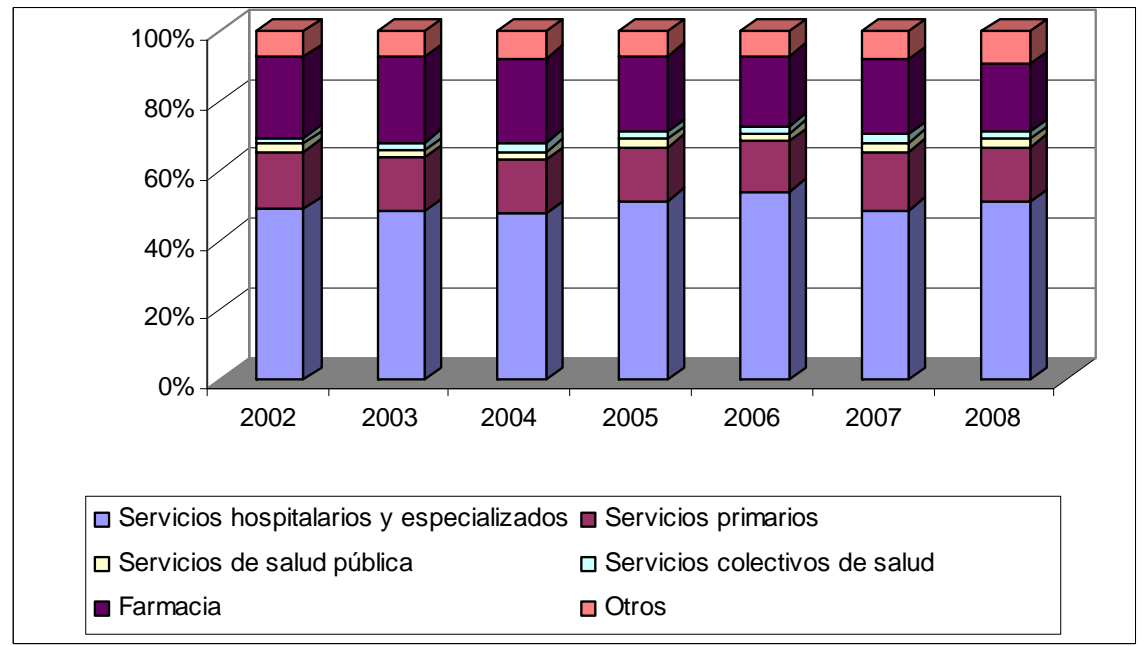

Nota: Servicios colectivos de salud incluye gasto en investigación y admón. Central.

\section{Tabla 5}

Indicadores de gasto: España vs Castilla y León

\begin{tabular}{|c|c|c|c|c|c|c|c|}
\hline & 1999 & 2000 & 2001 & 2002 & 2003 & 2004 & 2005 \\
\hline Población protegida por el SNS (miles): España & 37.980 & 38.281 & 38.905 & 39.618 & 40.498 & 40.983 & 41.928 \\
\hline Castilla y León & 2.317 & 2.308 & 2.307 & 2.308 & 2.317 & 2.322 & 2.341 \\
\hline Gasto sanitario por persona protegida: España & 721 & 776 & 818 & 876 & 956 & 1.023 & 1.091 \\
\hline Castilla y León & 726 & 787 & 840 & 898 & 1.029 & 1.093 & 1.177 \\
\hline Gasto sanitario por persona/PIB pc: España & 5 & 4,99 & 4,94 & 5,03 & 5,22 & 5,26 & 5,32 \\
\hline Castilla y León & 5,41 & 5,6 & 5,6 & 5,6 & 6,01 & 5,97 & 6,06 \\
\hline $\begin{array}{l}\text { Gasto sanitario por persona / Gasto público por } \\
\text { persona: España }\end{array}$ & 45 & 42,39 & 41,84 & 37,85 & 37,9 & 37,44 & 36,9 \\
\hline Castilla y León & 55,83 & 52,38 & 50,24 & 41,54 & 38,89 & 38,67 & 37,94 \\
\hline $\begin{array}{l}\text { Gasto en atención especializada por persona } \\
\text { protegida: España }\end{array}$ & 394 & 423 & 441 & 468 & 510 & 551 & 594 \\
\hline Castilla y León & 365 & 393 & 420 & 437 & 513 & 532 & 599 \\
\hline $\begin{array}{l}\text { Gasto sanitario en atención primaria por } \\
\text { persona protegida: España }\end{array}$ & 105 & 111 & 117 & 125 & 137 & 145 & 154 \\
\hline Castilla y León & 137 & 134 & 140 & 147 & 160 & 172 & 184 \\
\hline $\begin{array}{l}\text { Gasto sanitario en investigación y formación } \\
\text { por persona protegida: España }\end{array}$ & 1 & 1 & 1 & 1 & 1 & 2 & 2 \\
\hline Castilla y León & 0 & 0 & 0 & 0 & 0 & 3 & 2 \\
\hline $\begin{array}{l}\text { Gasto sanitario en farmacia por persona } \\
\text { protegida: España }\end{array}$ & 165 & 179 & 191 & 205 & 225 & 237 & 246 \\
\hline Castilla y León & 162 & 174 & 190 & 208 & 233 & 253 & 261 \\
\hline
\end{tabular}

Fuente: Informe del grupo de trabajo de análisis del gasto sanitario (2007). 
Ese mismo informe recoge también datos significativos sobre el gasto sanitario en atención a distintos criterios, observando las diferencias entre la media nacional y la de la Comunidad, así como la evolución temporal (Tabla 5). En casi todos los componentes de gasto sanitario definidos por persona protegida, la cifra de la Comunidad supera a la media nacional.
En el caso del gasto farmacéutico, la Tabla 6 recoge los datos sobre la población protegida de farmacia en el SNS en el período 1999-2005 -con un incremento del $10 \%$ a nivel nacional y del $1 \%$ en la Comunidad-y la Tabla 7 resume los principales indicadores medios a nivel nacional y de Castilla y León.

\section{Tabla 6}

Población protegida de farmacia en el SNS

\begin{tabular}{|l|c|c|c|c|c|c|c|}
\hline & 1999 & $\mathbf{2 0 0 0}$ & $\mathbf{2 0 0 1}$ & $\mathbf{2 0 0 2}$ & $\mathbf{2 0 0 3}$ & $\mathbf{2 0 0 4}$ & $\mathbf{2 0 0 5}$ \\
\hline $\begin{array}{l}\text { Castilla y } \\
\text { León }\end{array}$ & 2.295 .857 & 2.286 .960 & 2.286 .600 & 2.288 .079 & 2.295 .241 & 2.300 .678 & 2.318 .882 \\
\hline $\begin{array}{l}\text { Total } \\
\text { nacional }\end{array}$ & 37.701 .409 & 38.005 .649 & 38.635 .900 & 39.350 .916 & 40.229 .889 & 40.717 .076 & 41.666 .798 \\
\hline
\end{tabular}

Tabla 7

Indicadores de gasto farmacéutico: España vs Castilla y León

\begin{tabular}{|l|c|c|}
\hline & 1999 & $\mathbf{2 0 0 5}$ \\
\hline Gasto por receta & 10,99 & 13,15 \\
Total Nacional & 11,05 & 13,78 \\
Castilla y León & & \\
\hline Recetas por personal en el SNS & 15,1 & 18,35 \\
Total Nacional & 14,36 & 18,66 \\
Castilla y León & & \\
\hline \% aportación sobre importe facturado por el SNS & 7,36 & 6,26 \\
Total Nacional & 6,9 & 5,41 \\
\hline Castilla y León & & \\
\hline
\end{tabular}

\subsection{Situación actual: León en perspectiva}

Para completar los datos de los apartados anteriores, es conveniente comparar las cifras observadas en la provincia de León con la media de la Comunidad de Castilla y León, especialmente considerando que algunos indi- cadores básicos de centros hospitalarios e indicadores de dotación muestran que la situación de nuestra Comunidad Autónoma es óptima frente a la media nacional (Tabla 8). Así se desprende a la vista de las cifras obtenidas en la última Estadística de Indicadores Hospitalarios, referida a 2005, elaborada por el INE. 
Tabla 8

Indicadores básicos 2005

\begin{tabular}{|c|c|c|}
\hline & Castilla y León & España \\
\hline \multicolumn{3}{|l|}{ Indicadores básicos de centros hospitalarios } \\
\hline Hospitales por 100.000 habitantes & 1,66 & 1,73 \\
\hline Ingresos por 1.000 habitantes & 119,46 & 117,56 \\
\hline Altas por 1.000 habitantes & 119,87 & 117,43 \\
\hline Estancias por 1.000 habitantes & $1.145,71$ & 994,78 \\
\hline Consultas externas por 1.000 habitantes & $1.240,57$ & $1.270,59$ \\
\hline Urgencias por 1.000 habitantes & 420,36 & 562,14 \\
\hline Actos quirúrgicos por 1.000 habitantes & 81,30 & 97,31 \\
\hline Compras y gastos (€/habitante) & 597,82 & 652,15 \\
\hline Ingresos y financiación (€/habitante) & 597,24 & 655,59 \\
\hline Capacidad media hospitales & 254,39 & 209,59 \\
\hline Estancia media (días) & 9,56 & 8,47 \\
\hline Índice de rotación & 30,20 & 34,95 \\
\hline \% ocupación & 79,07 & 81,11 \\
\hline Actos quirúrgicos/Quirófano en funcionamiento & $1.005,40$ & $1.145,74$ \\
\hline Partos por cama en obstetricia & 54,89 & 67,89 \\
\hline Necropsias/100 fallecidos & 1,89 & 3,60 \\
\hline Personal total /Camas en funcionamiento & 2,45 & 2,92 \\
\hline Personal sanitario/Camas & 1,74 & 2,10 \\
\hline Personal médico/Camas & 0,36 & 0,44 \\
\hline Personal enfermería/Camas & 0,71 & 0,83 \\
\hline Personal ayudantes sanitarios/Camas & 0,65 & 0,79 \\
\hline Personal no sanitario/Camas & 0,71 & 0,82 \\
\hline \multicolumn{3}{|l|}{ Otros Indicadores de dotación } \\
\hline Camas instaladas por 10.000 habitantes & 42,17 & 36,27 \\
\hline Quirófanos en funcionamiento por 10.000 habitantes & 8,09 & 8,49 \\
\hline Incubadoras en funcionamiento por 10.000 niños nacidos en el año & 70,47 & 57,99 \\
\hline Paritorios en funcionamiento por 10.000 mujeres en edad fértil & 0,72 & 0,65 \\
\hline
\end{tabular}

Fuente: Elaboración propia a partir de información suministrada por el INE.

Además de los datos previos, la consulta del Catálogo de Centros de Atención Primaria y del Catálogo Nacional de Hospitales permite actualizar la información sobre los recursos disponibles en la provincia de León y en la Comunidad Autónoma, que se resumen en la Tabla 9, mientras que el Gráfico 11 representa la distribución por provincias: 
Tabla 9

Recursos sanitarios a 31 de diciembre de 2011

\begin{tabular}{|c|c|c|c|}
\hline & León & Castilla y León & España \\
\hline Atención primaria: & & & 2.297 \\
Centros de salud & 39 & 728 & 10.168 \\
Consultorios & 728 & 3762 & 790 \\
& & 30 generales & \\
Número de hospitales & 10 & 4 geriatría & \\
\hline Camas instaladas & 2.252 & 9.683 & \\
\hline
\end{tabular}

Fuente: Elaboración propia a partir de datos del Ministerio de Sanidad y Consumo.

\section{Gráfico 11}

Atención primaria y hospitales en Castilla y León (2011)

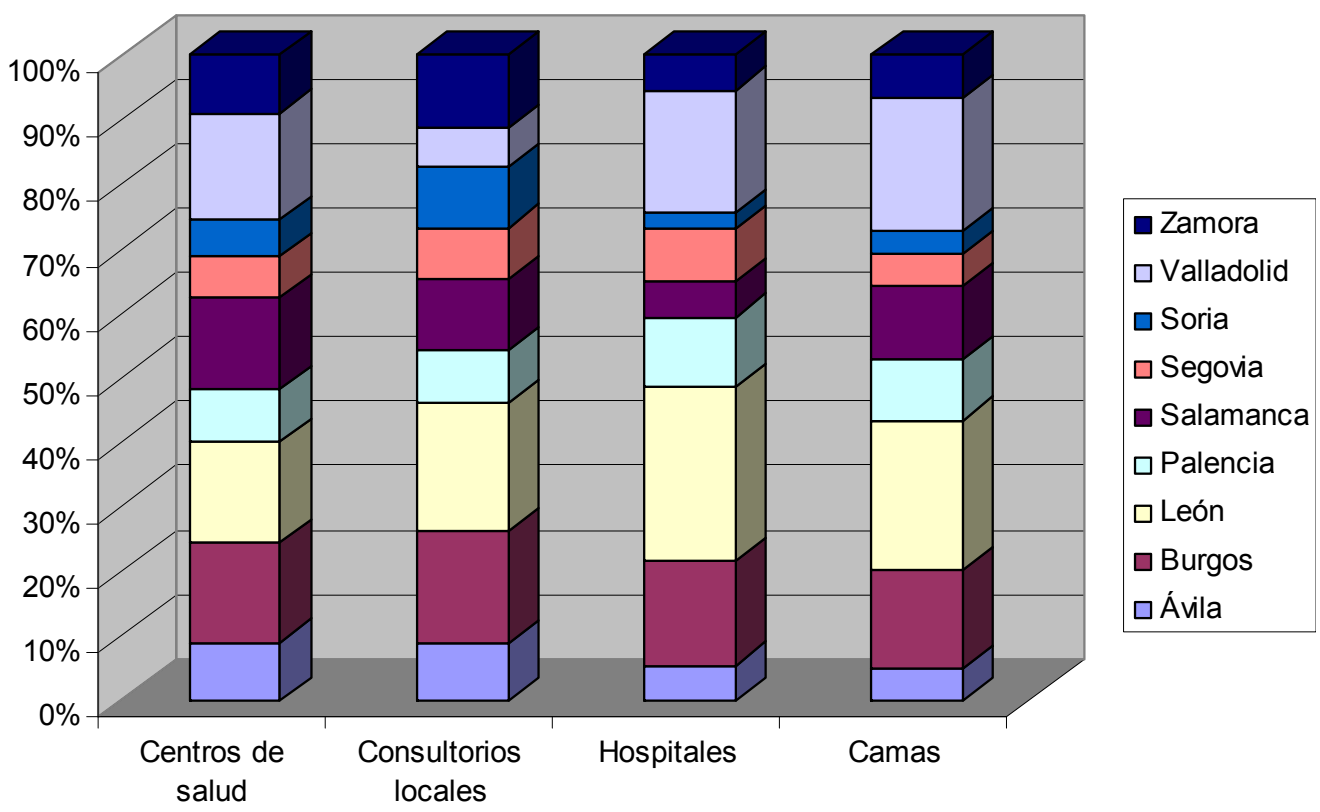

Fuente: Elaboración propia a partir de datos del Ministerio de Sanidad y Consumo.

En atención primaria, León ocupa el primer lugar de la Comunidad, pues es la provincia con mayor número de centros de salud por detrás de Valladolid, al contar con 39 de los 247 centros de la Comunidad Autónoma, y dispone de 728 consultorios. Además, es la provincia con mayor número de hospitales y de camas instaladas. En cuanto a dotación de recursos, la provincia dispone de 222,5 camas/hospital, nivel inferior a la media regional $(261,47)$.

La Tabla 10 amplía la información sobre la provincia de León a partir de la consulta del último Catálogo Nacional de Hospitales que recoge datos referidos a 31 de diciembre de 2011. 
Tabla 10

Hospitales en León (2011)

\begin{tabular}{|c|c|c|c|c|c|c|}
\hline & Camas & Fin. asist. & $\begin{array}{c}\text { Dep. } \\
\text { funcional }\end{array}$ & $\begin{array}{l}\text { Dep. } \\
\text { patrim. }\end{array}$ & Concierto* & $\begin{array}{l}\text { Acred. } \\
\text { docente }\end{array}$ \\
\hline Clínica Ponferrada & 45 & General & Privado & Privado & $X$ & \\
\hline Hospital de la Reina & 88 & General & Privado & Priv-benéf. & $\mathrm{X}$ & \\
\hline Hospital El Bierzo & 408 & General & Sacyl & $\begin{array}{c}\text { Seg.social } \\
\text { SACYL }\end{array}$ & & $X$ \\
\hline Hospital San Juan de Dios & 297 & General & $\begin{array}{l}\text { Priv-benéfi. } \\
\text { (Iglesia) }\end{array}$ & Priv-benéf. & $x$ & \\
\hline Hospital Valle de Laciana & 20 & $\begin{array}{l}\text { Geriatría y/o } \\
\text { larga estancia }\end{array}$ & $\begin{array}{l}\text { Comunidad } \\
\text { Autónoma }\end{array}$ & $\begin{array}{l}\text { Comunidad } \\
\text { Autónoma }\end{array}$ & $x$ & \\
\hline Clínica Altollano & 114 & General & Privado & Privado & $x$ & \\
\hline Sanatorio López Otazu, S.L. & 45 & General & Privado & Privado & $X$ & \\
\hline $\begin{array}{l}\text { Complejo Asistencial de León } \\
\text { Hospital Santa Isabel } \\
\text { Hospital Monte San Isidro } \\
\text { Hospital de León }\end{array}$ & 1021 & General & Sacyl & $\begin{array}{c}\text { Entid.públic } \\
\text { as } \\
\text { SACYL }\end{array}$ & & $x$ \\
\hline Clínica San Francisco & 104 & General & Privado & Privado & $\mathrm{X}$ & \\
\hline Obra Hospit.Ntra.Sra. de Regla & 110 & General & $\begin{array}{c}\text { Priv-benéfico } \\
\text { (Iglesia) }\end{array}$ & $\begin{array}{c}\text { Priv.benéfic } \\
0\end{array}$ & $x$ & \\
\hline & 2.252 & & & & & \\
\hline
\end{tabular}

${ }^{*}$ Se entiende por concierto un contrato realizado entre un establecimiento sanitario (privado o público) y el organismo responsable de gestionar la asistencia sanitaria de la Seguridad Social, por el cual se determinan, bajo ciertas condiciones, las características y las tarifas de cada uno de los servicios sanitarios concertados.

Fuente: Elaboración propia a partir del Catálogo General de Hospitales (2011).

Por último, la Tabla 11 resume la dotación de equipos de alta tecnología en los hospitales de León respecto al total de la Comunidad Autónoma (2011), que suponen 106 aparatos totales de los 440 de Castilla y León $(24,09 \%)$ :

A la vista de todo lo anterior, la dotación de recursos en la provincia de León se muestra inicialmente como una de las principales fortalezas de su sistema sanitario, tanto en la atención primaria como hospitalaria. Además, las estancias en hospitales han ido disminuyendo en los últimos años, buen reflejo de la mejora en la calidad de vida.

Sin embargo, algunos aspectos merecen ser destacados como potenciales debilidades para la provincia. Así, pese a contar con el mayor número de hospitales de la Comunidad Autónoma y haber alcanzado notables ratios de recursos disponibles, esos indicadores deben vigilarse.

En las últimas cifras disponibles, de 31 de diciembre de 2011, el número de camas medias por hospital se sitúa bastante por debajo de las cifras de otras provincias. Asimismo, León sufre los efectos de la tendencia a la especialización hospitalaria en determinados lugares. De los 37 centros hospitalarios, Castilla y León dispone de cuatro centros de geriatría (Burgos y León) y tres psiquiátricos (Palencia y Segovia), siendo el resto generales. Por tanto, de los 10 hospitales de la provincia leonesa, sólo uno es especializado (geriatría y/o larga estancia). 
Tabla 11

Dotación tecnológica en León (2011)

\begin{tabular}{|c|c|c|c|c|c|}
\hline & León & $\begin{array}{l}\text { Media por } 100 \\
\text { camas }\end{array}$ & $\begin{array}{c}\text { Castilla y } \\
\text { León }\end{array}$ & $\begin{array}{l}\text { Media por } 100 \\
\text { camas }\end{array}$ & $\begin{array}{c}\text { Total } \\
\text { nacional }\end{array}$ \\
\hline Tomografía axial computerizada & 10 & 0,44 & 38 & $0,39 *$ & 690 \\
\hline Resonancia magnética & 8 & 0,36 & 28 & 0,29 & 492 \\
\hline Gammacámara & 3 & 0,13 & 12 & 0,12 & 237 \\
\hline Sala de hemodinámica & 2 & 0,09 & 8 & 0,08 & 233 \\
\hline Angiografía por sustracción digital & 1 & 0,04 & 6 & 0,07 & 195 \\
\hline $\begin{array}{l}\text { Litotricia extracorpórea por ondas de } \\
\text { choque }\end{array}$ & 2 & 0,09 & 3 & 0,03 & 93 \\
\hline Bomba de cobalto & 0 & - & 1 & 0,01 & 28 \\
\hline Acelerador de partículas & 2 & 0,09 & 11 & 0,12 & 192 \\
\hline Tomografía por emisión de fotones & 1 & 0,04 & 2 & 0,02 & 63 \\
\hline Tomografía por emisión de positrones & 0 & - & 0 & - & 55 \\
\hline Mamógrafo & 12 & 0,53 & 47 & 0,48 & 563 \\
\hline Densitómetros óseos & 6 & 0,27 & 15 & 0,15 & 218 \\
\hline Equipos de hemodiálisis & 56 & 2,49 & 269 & 2,78 & 4259 \\
\hline Total & 103 & & 440 & & 7.318 \\
\hline
\end{tabular}

Fuente: Elaboración propia a partir de datos del Ministerio de Sanidad y Consumo.

* (38/9539)*100.

Nota: los complejos hospitalarios y ciudades sanitarias se contabilizan como un solo hospital.

\section{Conclusiones}

Durante el siglo pasado, el modelo sanitario español avanzó hacia la universalidad de la atención sanitaria, la progresiva financiación mediante presupuestos generales y el traspaso de competencias a las Comunidades Autónomas. Simultáneamente, se ha ido enfrentando a importantes problemas de financiación derivados de factores demográficos, como el envejecimiento de la población y el incremento de la demanda asistencial, y de las propias debilidades del sistema de financiación. El sistema sanitario, que representa alrededor del $40 \%$ del presupuesto de las Comunidades, se ve aquejado no tanto de un exceso de gasto -si consideramos las prestaciones garantizadas- como de insuficiencia de ingresos fiscales y, en definitiva, de los problemas derivados que la sanidad española no disponga de un presupuesto específico.

El sistema sanitario español, considerado uno de los más completos y eficientes del mundo, afronta, sin embargo, un escenario de recortes -y no sólo reformas- que cuestiona sus principios básicos, dejando a un lado su anterior universalidad, fomentando las fórmulas de copago y la privatización de la gestión sanitaria, y apostando por una política de austeridad no sólo en medios materiales sino también humanos que sin duda conllevará una asistencia sanitaria de peor calidad, el aumento de las listas de espera y, en definitiva, un paso más en el menoscabo de nuestro estado del bienestar.

La evolución de los principales indicadores sanitarios en la provincia de León y en la Comunidad Autónoma de Castilla y León desde 1986 debe centrarse en los recursos disponibles -establecimientos sanitarios, dotación instalada y factor humano-, además de datos sobre financiación y gasto sanitario.

En los 25 años a los que se refiere el estudio, el número de hospitales en la provincia ha disminuido de 25 a 10 , y se ha producida una concentración de especialidades en determinadas provincias de la Comunidad, lo que explica que actualmente 9 de esos hospitales 
sean generales, es decir, sin especialización en una determinada área o destinados a pacientes afectos de patología variada.

La dotación instalada sigue esa misma línea decreciente, pues el número de camas ha disminuido más de un $19 \%$ a lo largo del período, y la media de la provincia $(215,6$ camas/hospital en 2010) se sitúa por debajo de la Comunidad aunque es superior a los datos nacionales. Con relación a la población, los hospitales de León cuentan con 0,00432 camas por habitante. Por su parte, la actividad asistencial en régimen hospitalario se mide a través de las estancias en hospitales, que van disminuyendo (200.000 estancias menos en 2008 frente a 1986), manteniendo siempre un número superior en los varones frente a las mujeres.

En lo relativo a los recursos humanos, como último elemento de los recursos disponibles, León cuenta en 2009 con el 17,22\% de los médicos colegiados de Castilla y León.

La financiación y gasto sanitario antes mencionados, que permiten el desarrollo de todas estas actividades, muestran, según el último "Informe del grupo de trabajo de análisis del gasto sanitario" el gasto sanitario de la Comunidad representa el $5,65 \%$ del PIB en 2005 (frente a la media nacional del 5,05\%) y supone el $35,37 \%$ del gasto público. La mayor parte del gasto se concentra en servicios hospitalarios y especializados, seguidos del gasto en farmacia.

Por último, los informes publicados en 2011 ofrecen los datos más actualizados sobre la provincia, indicando, además de los 10 hospitales mencionados, que contamos con 39 centros de salud y 728 consultorios de atención primaria. De este modo, León ocupa el segundo lugar en la Comunidad en dotación de centros de salud por detrás de Valladolid. Además, es la primera provincia a nivel de atención primaria, y la que cuenta con más hospitales y dotación de camas instaladas. No obstante, estas cifras absolutas esconden una baja ratio de dotación de recursos, ya que sólo en la provincia de Segovia el indicador camas/ hospital es inferior.

Todos estos datos indican la necesidad de potenciar la coordinación de un sistema de gestión descentralizado como el que actualmente caracteriza nuestro SNS para reforzar y ofrecer garantía del futuro de la sanidad pública española. Además, la creciente participación de compañías aseguradoras y el avance hacia un modelo de gestión del sistema sanitario público con participación privada no ha demostrado, por el momento, mejores resultados que la gestión enteramente pública. De no adoptarse medidas urgentes, el sistema sanitario español parece caminar hacia una creciente diferenciación y desigualdad para diferentes grupos de población, acentuando, en último término las desigualdades sociales.

Próximamente se verá el efecto de los recortes en el sector no sólo sobre estos indicadores, sino particularmente sobre la calidad de la asistencia sanitaria y el modelo universal de sanidad pública conquistado hasta ahora.

\section{Referencias}

Angora Mazuecos, F. y Salve Díaz-Miguel, Ma J. (2011). Periplo en torno a la gestión sanitaria. En, L. Palomo (Coord.), 30 años del sistema sanitario español (1981-2010), (pp. 123-134). Madrid: FADSP, Federación de Asociaciones para la Defensa de la Sanidad Pública.

Barlow, J. y Roehrich, S. (2013). Europe sees mixed results from public-private partnerships for building and managing health care facilities and services. Health Affairs, 32(1), 146-154.

Benach, J., Tarafa. G. y Muntaner, C. (2012). El copago sanitario y la desigualdad: ciencia y política. Gaceta Sanitaria, 26(1), 80-82.

Campos, A.I. y Aguiar, A.C. (2013). ¿Es necesaria una segunda reforma de la atención primaria en España? Ciênc. Saúde Coletiva [online], 18(1) 17-23. 
De la Fuente, A. (2012). ¿Qué reformas necesita el sistema de financiación regional? Papeles de Economía Española, (133), 153-163.

Directiva 89/105/CEE del Consejo, de 21 de diciembre, de transparencia de las medidas que regulan la fijación de precios de los medicamentos para uso humano y su inclusión en el ámbito de los sistemas nacionales del seguro de enfermedad.

Evans, R.G. (2007). Economic myths and political realities. Vancouver: University of British Columbia, Centre for Health Services and Policy Research.

Gallego Peragón, J.M. (2011). Medidas sobre racionalización en el gasto destinado a financiar las prestaciones farmacéuticas. Presupuesto y Gasto Público, (65), 27-50.

García Armesto, S., Abadía, B., Durán, A., Hernández-Quevedo, C. y Bernal, E. (2010). España. Análisis del Sistema Sanitario 2010. Observatorio Europeo de Sistemas y Políticas de Salud, Organización Mundial de la Salud.

Herrero Alcalde, A. y Tránchez Martín, J.M. (2011). El desarrollo y evolución del sistema de financiación autonómica. Presupuesto y Gasto Público, (62), 33-65.

INE (1987-2009). Series históricas de población: población de derecho.

INE (1996-2005). Estadística de indicadores hospitalarios. Recuperado de http://www.ine.es.

INE (1997-2010). Estadística de profesionales sanitarios colegiados. Recuperado de http://www.ine.es

INFORME SESPAS (Sociedad española de salud pública y administración sanitaria) 2012.

Junta de Castilla y León (1987-2011). Anuarios Estadísticos de Castilla y León. Consejería de Economía y Hacienda.

Jurado, I. (2012). Actitudes, uso y propuestas sobre el Sistema sanitario español. Encuentros multidisciplinares, 14(41), 34-47.

Lamata Cotanda (2011). Ventajas e inconvenientes de la descentralización sanitaria. En, L. Palomo (Coord.), 30 años del sistema sanitario español (1981-2010), (pp. 103-112). Madrid: FADSP.

Ley 1/1993, de 6 de abril, de Ordenación del Sistema Sanitario.

Ley 14/1986, de 25 de abril, General de Sanidad.

Ley 15/1990, de 9 de julio, de ordenación sanitaria.

Ley 15/1997, de 25 de abril, sobre habilitación de nuevas formas de gestión del Sistema Nacional de Salud.

Ley 25/1990, de 20 de diciembre, del medicamento.

Ley 16/2003, de 26 de mayo, de cohesión y calidad del Sistema Nacional de Salud.

Ley 44/2003, de 21 de noviembre, de ordenación de las profesiones sanitarias.

Ley 55/2003, de 16 de noviembre, del Estatuto marco del personal sanitario de los servicios de salud.

Ley $21 / 2011$, de 27 de diciembre, por la que se regulan las medidas fiscales y administrativas del nuevo sistema de financiación de las Comunidades Autónomas de régimen común y Ciudades con Estatuto de Autonomía.

Ley Orgánica 4/1983, de 25 de febrero, Estatuto de Autonomía de Castilla y León. (BOE de 2 de marzo).

Ley Orgánica 9/1992, de 23 de Diciembre, de Transferencia de Competencias a Comunidades Autónomas que accedieron a la Autonomía por la Vía del Artículo 143 de la Constitución.

La Ley Orgánica 7/2001, de 27 de diciembre, de modificación de la Ley Orgánica 8/180, de financiación de las CCAA (LOFCA), 
López Casanovas, G. (2010). Las cifras del gasto sanitario en su comparativa. Errores y omisiones. Gestión Clínica y Sanitaria, 12(1), 27-29.

López Saludas, J.M. (2013). Efecto de los copagos en la sanidad: teoría y evidencia. Boletín Económico del ICE, (3035), 43-52.

López-Fernández, L.A., Martínez Millán, J.I., Fernández Ajuria, A., March Cerdà, J.C., Suess, A. y Prieto Rodríguez, $\mathrm{M}^{\mathrm{a} A}$. (2012). ¿Está en peligro la cobertura universal en nuestro Sistema Nacional de Salud?, Gaceta Sanitaria, 26(4), 298-300.

Martín Martín, J.J. y López del Almo González, M.P. (2011). La sostenibilidad del Sistema Nacional de Salud en España. Cien Saude Colet, 16(6), 2773-82.

Mas, N., Cirera, L. y Viñolas, G. (2011). Los sistemas de copago en Europa, Estados Unidos y Canadá: implicaciones para el caso español. IESE Business School.

Ministerio de Sanidad y Consumo (2005; 2007). Catálogo nacional de hospitales; http://www.msc.es.

Ministerio de Sanidad y Consumo (2007). Informe del Grupo de Trabajo de análisis del gasto sanitario. Sistema de información sanitaria del SNS. Recuperado de http://www.msc.es.

Ministerio de Sanidad, Servicios Sociales e Igualdad (2011). Barómetro Sanitario 2011. Instituto de Información Sanitaria, Centro de Investigaciones Sociológicas.

Periró, S. y Meneu, R. (2013). Eficiencia en la gestión hospitalaria pública: directa vs privada por concesión, Recuperado de http://www.fedeablogs.net/economia/?p=27263 (en línea).

Real Decreto 1480/2001, de 27 de diciembre, sobre traspaso a la Comunidad de Castilla y León de las funciones y servicios del Instituto Nacional de Salud.

Real Decreto 840/2002, de 2 de agosto, por el que se modifica y desarrolla la estructura orgánica básica del Ministerio de Sanidad y Consumo.

Real Decreto-ley 4/2010, de 26 de marzo, de racionalización del gasto farmacéutico con cargo al SNS.

Real Decreto-ley 8/2010, de 20 de mayo, por el que se adoptan medidas extraordinarias para la reducción del déficit público.

Real Decreto-ley 16/2012, de 20 de abril, de medidas urgentes para garantizar la sostenibilidad del Sistema Nacional de Salud y mejorar la calidad y seguridad de sus prestaciones (BOE 24 de abril de 2012).

Rey del Castillo, J. (2011). Cambios legislativos sanitarios más importantes en los últimos 30 años. En, L. Palomo (Coord.), 30 años del sistema sanitario español (1981-2010), (pp. 87-102). Madrid: FADSP.

Rey del Castillo, J. (2012). El futuro de la protección sanitaria en España en el contexto de la crisis económica y el marco europeo. Encuentros Disciplinares, 14(1), 62-80.

Sánchez Bayle (2011). Evolución de la financiación sanitaria 1981-2010. En, L. Palomo (Coord.), 30 años del sistema sanitario español (1981-2010), (pp. 79-86). Madrid: FADSP.

Sánchez F.I., Abellán, J.Ma y Oliva, J. (2013). Gestión pública y gestión privada de servicios sanitarios públicos: más allá del ruido y la furia, una comparación internacional. Documento de trabajo 4/2013, Real Instituto Elcano.

Simó Miñana, J. (2011). El gasto farmacéutico público en España durante los últimos treinta años, consideraciones para su valoración. En, L. Palomo (Coord.), 30 años del sistema sanitario español (1981-2010), (pp. 137-154). Madrid: FADSP. 